This item was submitted to Loughborough's Research Repository by the author.

Items in Figshare are protected by copyright, with all rights reserved, unless otherwise indicated.

\title{
Correlation of acoustic emissions with patterns of movement in an extremely slow moving landslide at Peace River, Alberta, Canada
}

PLEASE CITE THE PUBLISHED VERSION

https://doi.org/10.1139/cgj-2016-0668

\section{PUBLISHER}

NRC Research Press (@ The Authors)

\section{VERSION}

AM (Accepted Manuscript)

\section{PUBLISHER STATEMENT}

This work is made available according to the conditions of the Creative Commons Attribution-NonCommercial 4.0 International (CC BY-NC 4.0) licence. Full details of this licence are available at: https://creativecommons.org/licenses/by-nc/4.0/

\section{LICENCE}

CC BY-NC 4.0

\section{REPOSITORY RECORD}

Berg, Nancy, Alister Smith, Shawn Russell, Neil Dixon, Don Proudfoot, and Andrew Take. 2019. "Correlation of Acoustic Emissions with Patterns of Movement in an Extremely Slow Moving Landslide at Peace River, Alberta, Canada". figshare. https://hdl.handle.net/2134/28454. 
Correlation of acoustic emissions with patterns of movement in an extremely slow moving landslide at Peace River, Alberta, Canada

Nancy Berg ${ }^{1}$, Alister Smith ${ }^{2}$, Shawn Russell ${ }^{3}$, Neil Dixon ${ }^{2}$, Don Proudfoot ${ }^{3}$, W. Andy Take ${ }^{1}$

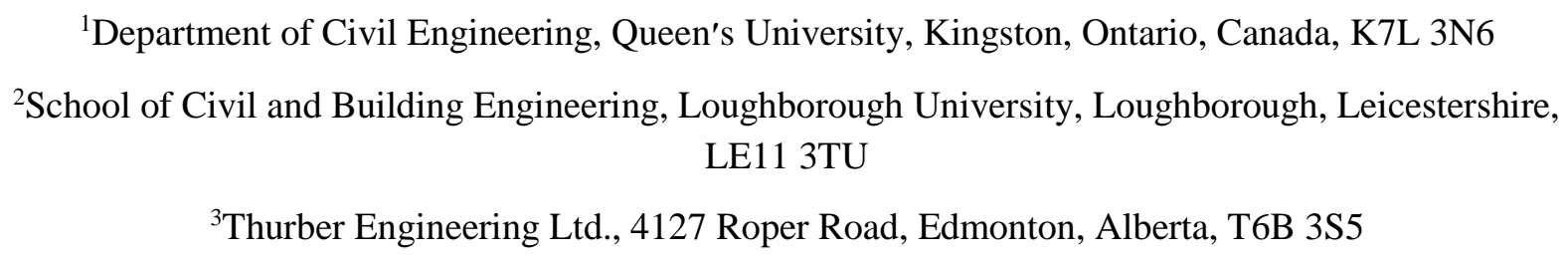

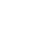

1

2

3

4

5

6

7

8




\section{Abstract}

30 The Peace River region, Alberta, Canada, has experienced extensive landslide activity since deglaciation.

31 Shear zones within weak lacustrine silt and clay layers typically experience continuous creep, damaging

32 highway and utilities infrastructure. However, occasionally, movement accelerates and potentially

33 catastrophic failures occur. Conventional deformation monitoring approaches provide incremental

34 measurements with low temporal resolution and do not necessarily allow rapid changes in stability to be

35 detected and communicated sufficiently in advance to provide early warning. The study objectives were

36 to: (i) acquire a long-term dataset of continuous deformation measurements with high temporal resolution

37 of a case study slope in Peace River; (ii) enhance understanding of a typical creeping Peace River slope's

38 behavior in response to climatic drivers; and (iii) investigate the potential of an Acoustic Emission (AE)

39 monitoring system to provide early warning of accelerating deformation behavior. ShapeAccelArray

40 (SAA) and AE instruments were installed, in addition to conventional inclinometers and piezometers.

41 Measurements show that the landslide is 'extremely slow', moving on average 5-mm annually, and reveal

42 seasonal activity with periods of acceleration and deceleration driven by pore-water pressures. Measured

43 AE correlated strongly with the rate and magnitude of SAA-measured displacement, demonstrating the

44 potential of the $\mathrm{AE}$ technique to warn of accelerating behavior. 


\section{$47 \quad 1 \quad$ Introduction}

\subsection{Background}

The Peace River region in Alberta, Canada, has experienced extensive landslide activity since deglaciation and is one of the most historically active landslide sites in Western Canada (Figure 1) (Davies et al., 2005; Morgan et al., 2012). This significant activity is due to the slopes of the river valley, which were formed during deglaciation, being much steeper and narrower than the preglacial valley, causing the slopes to progressively approach their preglacial geometry (Thurber, 1987).

An inventory of historic and active landslides in Peace River Alberta indicate that the shear zones of many landslides develop within the weak lacustrine silts and clays (Davies et al., 2005). The landslides move along these shear zones, typically with continuous creep, damaging highway and utilities infrastructure. Occasionally, movement accelerates, triggered by elevations in pore-water pressures, reaching high velocities and large displacements. These slope failures can be catastrophic if infrastructure is in the landslide's path. A typical slope failure in the Peace River region is shown in Figure 1d. A large failure in May 2013 damaged the highway infrastructure. An orthoimage of this 2013 failure, located at Site A (Figure 1b) is shown in Figure 2a. Two visible slope scarps are shown to be present at Site A and are labeled as failures 1 and 2 on Figure 2b. This failure resulted in Highway 744 being closed for several months, severely affecting transportation to and from the town. Other infrastructure at risk of landslide damage at this site include: a railway corridor, located downslope, and a gas pipeline located upslope of Highway 744.

Slope movements affecting infrastructure performance in the area have led to a suite of instrumentation being installed along the highway as part of an ongoing risk management program. Conventional monitoring approaches that have been used include annual visual inspections and bi-annual monitoring of inclinometers and piezometers. However, these provide incremental measurements with low temporal 
resolution and do not always allow rapid changes in stability to be detected and communicated sufficiently in advance to provide early warning. The objectives of this study were to: (i) acquire a longterm dataset of continuous deformation measurements with high temporal resolution of a case study slope near the town of Peace River, which, to the authors' knowledge, such data has not previously been published; (ii) enhance understanding of the slope's behavior in response to climatic drivers; and (iii) trial an Acoustic Emission (AE) monitoring system and investigate its potential to provide early warning of accelerating deformation behavior. The case study slope is highlighted as Site B in Figure 1b.

\subsection{Slope Behavior and Monitoring}

Monitoring slope displacement rate patterns allows the landslide behavior to be classified (Lerouil et al., 1996). Figure 3 shows the idealized relationship between displacement and time for slopes that are: approching failure, undergoing movemenet due to seasonal activity, or creep. The relationships shown in Figure 3 do not take into account progressive failure, strength softening, or the brittle versus ductile nature of the soil. The displacement rate of some slopes increases exponentially prior to failure (Figure 3a). When a slope is experiencing accelerating displacement behavior, the time to failure can be forecasted by graphing the inverse velocity versus time data and finding the location where an extrapolated curve intersects the time axis (Saito, 1965; Fukuzono, 1985; Bozzano et al., 2014). Figure $3 \mathrm{~b}$ shows the relationship between displacement and time of a slope undergoing seasonal movement. For this case, the inverse velocity versus time graph will undulate with one or more peaks in velocity throughout the year. Since the data plotted and extrapolated on the inverse velocity versus time plot does not cross the $\mathrm{x}$-axis, failure with accelerated displacements is not forecast for these seasonal movements. Figure $3 \mathrm{c}$ represents a slope that is experiencing continuous creep. The rate of displacement for a slope experiencing creep does not change with time and the inverse velocity versus time relationship is constant. A high-temporal resolution baseline of slope displacement rate measurements permits an 
assessment of whether an observed increasing displacement rate is likely seasonal, or indicative of impending failure.

Monitoring for slope risk management has historically been performed using incremental displacement and displacement rate measurements provided by manual surveys of inclinometer casings (Figure 4a) (e.g. Bressani et al., 2008; Massey et al., 2013; Stark and Choi, 2008). When higher temporal resolution is needed, In-Place Inclinometers (IPIs) can be permanently installed at the shear surface depth to provide continuous measurements of slip surface deformation (e.g. Simeoni and Mongiovi, 2007). A more recent development is ShapeAccelArrays (SAAs) (Figure 4b) (Dasenbrock et al., 2012; Abdoun et al., 2013), which comprise a linear array of micro-electro-mechanical systems (MEMS) sensors that monitor displacement continuously. The string of sensors is installed vertically into the borehole, and the instrument provides displacement measurements with high temporal resolution at each sensor (available SAA gauge lengths are $0.2,0.305$ and $0.5 \mathrm{~m}$ ) with the benefit that the exact location of the slip surface(s) need not be known prior to instrumentation. Surface deformation monitoring techniques, such as differential Global Positioning Systems (dGPS) (Malet et al., 2002; Jaboyedoff et al., 2004; Brunner et al., 2007; Macciotta et al., 2014), tiltmeters (Uhlemann et al., 2016) and surveys using Total Stations, are also available, but typically have limitations in accuracy or temporal resolution. Continuously read IPIs and SAAs provide the level of information required to detect rapid changes in stability for early warning; however, these instruments are relatively expensive, which limits their application to high risk sites where a sizable budget for monitoring and instrumentation is available. An AE subsurface displacement rate monitoring instrument (Slope ALARMS) (Figure 4c) has been developed to provide continuous real-time information with high temporal resolution at a lower cost than other technologies for use in early warning.

\subsection{Acoustic Emission (AE) Monitoring of Slopes}


120

121

122

123

124

125

126

127

128

129

130

131

Slope monitoring strategies using measurement and quantification of AE generated by deforming soil have been developed over a period of decades (e.g. Koerner et al., 1981; Chichibu et al., 1989; Nakajima et al., 1991; Rouse et al., 1991; Fujiwara et al., 1999; Dixon et al., 2003; Smith et al., 2014a,b,c; Smith \& Dixon, 2015; Dixon et al., 2015a,b; Smith et al., 2016a,b). Waveguides (e.g. steel tubes) are used to transmit AE from the subsurface to ground level with low attenuation. An approach has been developed that uses 'noisy' backfill material (e.g. gravel) placed around the waveguide, which generates quantifiable $\mathrm{AE}$ (i.e. $\mathrm{AE}$ is measured from the backfill material and not from the host slope material) as the slope deforms. AE monitoring of these 'active' waveguides offers many benefits over traditional deformation monitoring techniques, which include: the subsurface materials are low-cost and easily sourced, which enables them to be widely used; continuous and real-time measurements can be provided at relatively low-cost because of low-cost electronics; and they continue to operate at larger displacements $(>500 \mathrm{~mm}$ of shear surface displacement) than other conventional techniques (Dixon et al., 2015b; Smith et al., 2016a). The current version of the AE system cannot locate the shear surface depth; however, it is possible to do so if the full AE waveform was monitored and arrival times of wave modes were calculated (e.g. Spriggs 2005). This AE system does not monitor the full waveform but instead monitors ring-down counts (RDC), which reduces processing, storage and power requirements. This has allowed the development of a portable AE sensing system that can monitor continuously and operate for long durations in the field on battery power.

Active waveguides are installed in boreholes, or retrofitted inside existing inclinometer or standpipe casings, that intersect existing or anticipated shear surfaces beneath the slope, and they comprise the composite system of a steel tube with a granular backfill surround (Figure 4c). As the host slope deforms, the active waveguide deforms, and this causes particle-particle and particle-waveguide interactions to take place, which generate the AE. AE generation mechanisms include friction (rolling and sliding friction) 
and collisions (e.g. particle contact network rearrangement and release of contact stress as interlocking is overcome and regained) (Koerner et al., 1981; Michlmayr et al., 2013; Michlmayr \& Or, 2014).

147 Field trials and laboratory experiments (Smith et al., 2014a,b,c; Dixon et al., 2015a,b; Smith, 2015; Smith et al., 2016a) have established that there is a direct relationship between slope displacement rates and active waveguide-generated $\mathrm{AE}$ rates. Generated $\mathrm{AE}$ rates are proportional to applied displacement rates because an increasing rate of deformation (i.e. in response to increasing slope velocity) generates an

151 increasing number of particle-particle and particle-waveguide interactions per unit time. Each particle 152 interaction generates transient $\mathrm{AE}$ events, which combine and propagate along the waveguide where they 153 are monitored at the ground surface.

Slope ALARMS is a unitary battery operated AE slope displacement rate sensor. A piezoelectric transducer coupled to the waveguide at the ground surface converts the AE to an electrical signal, which

157 is processed by the AE sensor. The AE sensor amplifies the signal and attenuates frequencies outside of 158 the 20 to $30 \mathrm{kHz}$ range, removing low frequency $(<20 \mathrm{kHz})$ environmental background noise (e.g. traffic 159 and construction activity). The sensor records the number of times the waveform crosses a pre-

160 programmed voltage threshold level within pre-set time intervals; ring-down counts (RDC) per unit time 161 (AE rates). RDC are illustrated in Figure 5a where an RDC is detected when the waveform crosses the 162 voltage threshold level.

164 Figure 5b shows the relationship between measured AE rates and the velocity of slope movement from a 165 field trial in a shallow reactivated landslide at Hollin Hill, North Yorkshire, UK (Smith et al., 2014a). 166 The coefficient of proportionality needs to be calculated to determine the displacement rate of a slope 167 from recorded AE rates. The velocity at any given time is equal to the AE rate divided by the coefficient 168 of proportionality. The coefficient of proportionality is dependent on many variables associated with the 
monitoring system, including: the sensor sensitivity, which is controlled by the voltage threshold level

170

171

172

173

174 The AE system was trialed at the site near the town of Peace River to investigate the potential of the deposited on top of the lacustrine silts and clays (Davies et al., 2005). and signal amplification; the depth to the shear surface, which governs the magnitude of AE attenuation as it is transmitted from the subsurface to ground level (Smith et al., 2016b); and the geometry and properties of the active waveguide (Dixon et al., 2015a).

$$
\text { technique for monitoring 'extremely slow' (<15mm/yr) (Cruden \& Varnes, 1996) rates of slope }
$$
movement and to detect changes in rates of movement of this magnitude that could indicate accelerating behavior for use in early warning. To date, the lowest rate of movement measured by the technique has been 'very slow' (cm's/yr) (Dixon et al., 2015b). This trial has also allowed the examination of the performance of the $\mathrm{AE}$ technique in monitoring slides with deep shear surface(s), as the landslide near the town of Peace River has a deeper shear surface than those in previous trials. Furthermore, the system had never before been used in a comparable environment, with significant temperature variations (e.g. $+30^{\circ} \mathrm{C}$ to $-35^{\circ} \mathrm{C}$ ) and ground freezing.

\section{Landslide Test Site near the Town of Peace River}

\subsection{Geological Setting of Peace River}

The Town of Peace River is located in the Peace River Lowlands physiographic zone within the Interior Plains of Canada. The geological setting of the area is complex due to Holocene erosion and processes resulting from the late Wisconsin glacial event (11,000 to 85,000 B. P.). The advance of the Laurentide Ice Sheet during glaciation produced proglacial lakes, causing lacustrine sediments to be deposited in the area. The particle size of the sediments increases towards the surface with sand and gravel being 
193 The surficial geology of the area consists of a local veneer of eolian sand and silt overlaying lacustrine

194 fine sand and clay with mixed colluvial material on the slopes (Thurber, 2009). The overconsolidated

195 lacustrine clays and silts are a major lithologic component of the colluvial deposits in the area. The low

196 strength lacustrine clay is responsible for many of the slope stability problems in the Peace River region

197 (Davies et al., 2005) since the failure surfaces of many translational slides in the area are located in the

198 clay layer (Morgan et al, 2012).

200 These sediments overlay two bedrock formations, the Peace River Formation and the Shaftsbury

201 Formation. The Peace River Formation is the lower lying formation. It occurs along the bottom of the

202 Peace River Valley, and consists of silty shale, fine sandstone and silty interbeds (Davies et al., 2005).

203 The Shaftsbury Formation is an upper Lower Cretaceous unit and consists of silty shale and shale,

204 ironstone beds, bentonite partings and thin silty and sandy intervals (Thurber, 2009). Morgan et al. (2012)

205 present a full description of the geological setting for the large landslides observed in the Town of Peace

206 River, Alberta, including a vertical cross-section of the inferred Quaternary stratigraphy across the Peace

207 River valley approximately $1 \mathrm{~km}$ from the study site.

\subsection{The Test Site (Site B)}

210 Site B is one of seven sites located along Highway 744 that are currently being monitored for slope

211 instability. Site B consists of $200 \mathrm{~m}$ of highway located between chainage $57.7 \mathrm{~km}$ and $57.9 \mathrm{~km}$ and is

212 undergoing slide movement based on Cruden \& Varnes (1996) classification system. In May 1984,

213 Highway 744 was converted from a two-lane gravel road to a paved road, which permitted the first

214 instances of road cracking to be observed in 1988. Cement-stabilized stone columns were installed along

215 the length of the site between 1988 and 1992 to stabilize the slope. However, the slope remained unstable

216 and in 1992 settlement was observed along the downslope face of the installed columns. Inclinometers 
were installed in 1992 as part of an initial monitoring program. Slope movements continued between 1992 and 1996 and following a period of above average precipitation, the roadway dropped up to $1 \mathrm{~m}$, and a scarp crack began to form in the backslope above the highway. Further remediation took place in 1996 to 1997 (Diyaljee, 2014) consisting of realigning a portion of the highway and then installing a 180

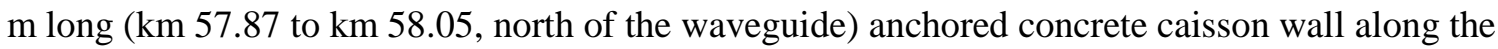
downslope edge of the re-aligned highway. The roadbed upslope of the wall was also excavated and rebuilt over lightweight fill (shredded tires) to reduce loads acting on the wall. A shear key and toe berm using lightweight fill consisting of shredded tires were later constructed below the highway in 1998, between $\mathrm{km} 57.77$ and $\mathrm{km} 57.92$ (downslope of the waveguide) to provide additional stability in that area. Since 1999, some settlement and cracking have been observed, as well as continued movements measured at depth by the inclinometers (Thurber, 2009). Currently, Site B comprises a series of $1 \mathrm{~m}$ to $4 \mathrm{~m}$ high scarps and several small slides, which are located downslope of the concrete pile wall.

Five conventional slope inclinometers and five piezometers were installed at Site B in March 2010 (Figure 6). Instrumentation cluster 8 (i.e. SI10-8 and PI10-8 in Figure 6a) is the focus of this study.

232 Inclinometer SI10-8 was retrofitted with an SAA in December 2014 to provide continuous subsurface

233 deformation measurements. An AE active waveguide was installed 1 m south-east of SI10-8 in July 2013

234 (Deep AE Sensor in Figure 6b). A second waveguide (Shallow AE Sensor) was installed 2 m south of the 235 Deep AE Sensor in October 2015 as part of a strategy to remove extraneous noise from the AE 236 measurements. Figures $6 \mathrm{c}$ and $6 \mathrm{~d}$ show the slope angle is approximately 17 degrees.

\subsection{Historical Inclinometer Measurements}

239 Figure 7a shows the plotted SI10-8 inclinometer data for the period between March 2010 to December 240 2014, and soil layering from the log of the borehole in which SI10-8 was installed. The shear surface is 
located approximately $16 \mathrm{~m}$ below the ground surface at an elevation of $498 \mathrm{~m}$. The total displacement measured at the shear surface by the inclinometer was $32.3 \mathrm{~mm}$ over this 1740 day period. The average displacement rate for this period was $0.018 \mathrm{~mm} /$ day $(6.6 \mathrm{~mm} / \mathrm{yr})$. The shear zone developed in the

244 lacustrine clay, which is consistent with other landslides in the area. The lacustrine clay at the shear

245 surface was very stiff due to the water content being close to or below the plastic limit. Despite the

246 stiffness of the clay it is a weak layer due to preshearing (Morgan et al., 2012)

\subsection{AE Instrumentation Installation}

\subsubsection{Deep AE Sensor}

250 The active waveguide (location in Figure 6) was installed in a $150 \mathrm{~mm}$ diameter borehole to a depth of 21

$251 \mathrm{~m}$ (Figure 7c). The waveguide consisted of a $38 \mathrm{~mm}$ diameter steel pipe with $4 \mathrm{~mm}$ wall thickness,

252 connected in $3.05 \mathrm{~m}$ lengths using screw-threaded couplings. The waveguide was placed in the centre of 253 the borehole, and the annulus was then backfilled. Subrounded $10 \mathrm{~mm}$ washed pea gravel was used to 254 backfill the lower portion of the borehole from the base up to $11.9 \mathrm{~m}$ below the ground surface. AEs are 255 predominantly generated in the zone of shearing, and therefore the active length with gravel backfill only needed to extend above and below the shear surface. A bentonite grout plug was used to seal against the ingress of water, which could potentially generate $\mathrm{AE}$ and contaminate the measurements. The bentonite

258 plug was produced using hydrated bentonite grout chips, which were used to backfill the annulus from

$25911.9 \mathrm{~m}$ to $8.8 \mathrm{~m}$ below ground level. The top portion of the annulus was then filled with borehole spoil

260 (Smith et al., 2014c). The waveguide extends $0.3 \mathrm{~m}$ above the ground surface and is enclosed in a locked 261 protective chamber that was initially comprised of black plastic culvert and a metal lid but was later 262 changed to a design consisting of white plastic culvert and a wooden lid in November 2015 (described in 263 Section 3.3.2). 


\subsubsection{Shallow AE Sensor}

266 The Deep AE Sensor measured extraneous noise, which contaminated the AE measurements. It was

267 suspected that this was caused by surficial processes related to low temperatures (e.g. frost heave) and/or

268 the cover responding to thermal effects. Extraneous noise in the AE data will be further discussed in

269 section 3.3.1. A Shallow AE Sensor (Figure 7c) was installed adjacent to the active waveguide, allowed

270 removal of AE measured from shallow sources from that measured by the Deep AE Sensor, thus isolating

271 AE generated only by subsurface ground movement. This waveguide used the same $38 \mathrm{~mm}$ diameter pipe

272 but only extended $3 \mathrm{~m}$ into the ground. The annulus around the waveguide was backfilled with auger

273 cuttings to replicate the upper portion of the Deep AE Sensor, and the same surface cover (white plastic

274 culvert and a wooden lid) was employed. Both AE measurement systems were configured to have a

$2750.25 \mathrm{~V}$ threshold level, and 1-hour monitoring intervals and both are powered by air alkaline batteries.

\subsection{SAA Installation}

The SAA was installed to provide continuous subsurface displacement measurements for comparison with AE measurements and to develop an enhanced understanding of the slope's behavior. The SAA extends from the ground surface to a depth of $20.1 \mathrm{~m}$ (Figure $7 \mathrm{~b}$ ) and has $0.305 \mathrm{~m}$ gauge lengths. The

281 SAA string was first installed inside $27 \mathrm{~mm}$ diameter unplasticized polyvinyl chloride (UPVC) conduit,

282 which was fastened together in $3 \mathrm{~m}$ lengths using epoxy, ensuring twisting of the SAA did not occur

283 (standard installation procedure). After the SAA had been secured within the UPVC conduit, it was

284 lowered inside the inclinometer casing, which had already been filled with bentonite-cement grout with 285 mix proportions of 1.0, 6.6 and 0.4 for Portland cement, water and bentonite respectively. This bentonite286 cement grout mix was selected to ensure it behaved comparably to the surrounding in situ soil. The 287 conduit was sealed to ensure it was watertight, and the SAA was connected to a datalogger, which is 288 powered by a battery and recharged by a solar panel. Initially, the measurement interval was set to 15 minutes to investigate noise in the data and ensure sufficient temporal resolution to capture the behavior 
of the slope. The period over which the rate of displacement varied was of the order of days, as opposed to minutes, and so the monitoring interval was increased to 2 hours, which also reduced the amount of data processed and hence battery usage during data transmission over a cellular modem.

\subsection{Piezometer Installation}

295 A pneumatic piezometer (PI10-8 in Figure 6a) was installed in March of 2010 at an elevation of $497 \mathrm{~m}$

296 (Figure 7d), which is within the lacustrine clay layer where the shear zone is located. The piezometer was

297 attached to the outside of the inclinometer casing installed at the same time, and the casing was then

298 tremie grouted using bentonite-cement grout from the bottom of the borehole to the ground surface.

299 Measurements were taken manually from the piezometer twice per year, except between December 2014

300 and November 2015 when the sampling frequency was increased due to site construction being performed 301 at Site A.

\section{$303 \quad 3 \quad$ Monitoring Slope Displacement}

\section{$304 \quad$ 3.1 SAA and Inclinometer Data}

305 The SAA data were averaged over 24 hour periods, and the weekly displacement measured with depth is 306 shown in Figure 7b. There is one failure surface located at a depth of approximately $16 \mathrm{~m}$. The failure 307 surface measured by the SAA agrees with the previously collected inclinometer data shown in Figure 7a.

308 Measurements taken after April 15, 2016, show negative movement occurring below the shear surface, 309 which is likely due to movement below the base of the SAA at the second shear surface, located at a 310 depth of $26 \mathrm{~m}$ (Figure 7a). Since the software used to process the SAA data assumes that the base of the

311 SAA remains stationary, if it is moving, MEMS nodes located below the shear surface that are

312 experiencing little or no movement will measure negative movement. Errors in the measured

313 displacement caused by the base of the sensor not remaining stationary do not affect the calculated 
314 incremental displacements, so the incremental displacement at each node can be used to correct for

315 measurement errors in the cumulative displacement measurements.

317 3.1.1 Relationship between Displacement, Precipitation and Piezometric Head

318 The cumulative displacement, cumulative total precipitation, and piezometric head between March 2010

319 and June 2016 are shown on Figure 8. By comparing precipitation (Figure 8a) and piezometric head

320 (Figure 8b), it can be seen that instances of heavy precipitation, such as the events that occurred between

321 June and September of 2011 and 2013 (circled areas on Figure 8), resulted in an increase in the

322 piezometric head. The piezometric head was very low at the beginning of 2011 and, despite a large

323 amount of precipitation, was lower than records over the subsequent 6.5 years. As a result, the smallest

324 magnitude of movement ( $3 \mathrm{~mm}$ ) occurred during 2011. The peak in piezometric head occurred in 2013 in

325 response to significant precipitation, causing $12 \mathrm{~mm}$ of shear surface displacement, which is more than

326 double the average yearly displacement measured between 2010 and 2016 of $5 \mathrm{~mm}$. This highlights the

327 important link between piezometric head and stability and demonstrates that it is not a simple process to

328 interpret changes in piezometric head from precipitation records alone.

330 Figure 9 shows the relationship between slope velocity and the piezometric head value. At low

331 piezometric head values (i.e. below $3 \mathrm{~m}$ of piezometric head) the velocity of slope deformation varied

332 independently of the pore-water pressure and movement could be interpreted as having been governed by

333 a constant rate of creep deformation. Carey et al (2015) found a similar trend between pore water

334 pressure and velocity for a site in southern England. At this site, a background creep deformation of

335 approximately $0.02 \mathrm{~mm} /$ day was observed that did not appear to respond to changes in pore water

336 pressure. At piezometric head readings above a threshold value of $3 \mathrm{~m}$, a linear relationship was found to

337 exist between the velocity of the slope and the piezometric head, with higher pore-water pressures leading 
to increases in the velocity of the slope. The slope of the linear regression through the velocities was found to be $0.015 \mathrm{~mm} /$ day per $\mathrm{m}$ of piezometric head. It should be noted that the linear relationship between slope velocity and piezometric head will not continue indefinitely, as higher piezometric levels than observed during the study period, could result in acceleration as the slope approaches failure.

\subsection{Interpretation of Slope Behavior}

344 Traditional inclinometer measurements at the site had a low temporal resolution (biannual readings)

345 which prevented a full observation of the seasonality of the slope's deformation behavior. Continuous

346 SAA shear surface displacement measurements for the period January 2015 to April 2016 are shown in

347 Figure 10a. This data indicates that the slope is continuously deforming, but at variable rates through the

348 year. To further investigate the seasonality of the deformation, the 60-day moving average inverse

349 velocity is plotted in Figure 10b. This moving average period was selected as it is a multiple of one month

350 and, given the extremely slow rate of movement, captures the deformation behavior with sufficient

351 temporal resolution. The cyclic nature of the inverse velocity data shows that the slope is experiencing

352 seasonal movement superimposed on top of continuous creep. The piezometric head was fairly constant

353 between January and November of 2015, varying by less than $0.3 \mathrm{~m}$, with peaks in the piezometric head

354 occurring in January and May. Accelerated slope movement occurred in January, April, and August. The

355 relationship between piezometric head and displacement rate at this site is complex, due to the continuous

356 creep, and further study is required to understand fully the effect small changes in piezometric head have

357 on slope displacement.

\subsubsection{Raw AE Data}


Data from the Deep AE Sensor has been collected continuously since July of 2013, with two gaps due to battery failure between July $22^{\text {nd }}$ and October $9^{\text {th }}$ of 2014 and November $1^{\text {st }}$ and December $9^{\text {th }}$ of 2014 . Figure 11a shows the raw AE rate data, and Figure 11b shows the cumulative AE record and the cumulative slope displacement. AE generated by periods of slope movement are expected to follow trends comparable to slope behavior, with characteristic S-shaped cumulative AE records as the slope accelerates, decelerates and then becomes stable again (Smith et al., 2014a; Dixon et al., 2015a; Uhlemann et al., 2016). Individual spikes of AE and AE that does not follow trends comparable to slope behavior are generated by spurious noise. Although there are several points in the cumulative data that resemble an S-shaped curve, many of these jumps are due to a single data spike generated by extraneous noise, which is why the cumulative AE does not line up with the cumulative displacement data (Figure $11 b)$.

\section{Environmental factors such as precipitation and temperature were investigated to develop an} understanding of the causes of extraneous AE noise. Figure 11c shows the daily total precipitation since July 2013. By comparing Figure 11c to 11 b, it can be seen that the cumulative AE and the cumulative precipitation do not follow the same trend, which indicates that precipitation does not generate noise in the AE measurements through impact with the cover or surface infiltration since large spikes in the $\mathrm{AE}$ did not coincide with large precipitation events. Figure $11 \mathrm{~d}$ shows the hourly change in temperature. It was found that a larger number of AE spikes occurred in the data during the winter of 2013/2014 when the temperature fluctuated by a larger amount than during the winters of $2014 / 2015$ or $2015 / 2016$. Large AE spikes occurred in February of 2014 and March of 2015 when the temperature fluctuated around zero degrees Celsius, indicating that temperature dependent factors such as freeze thaw cycles and frost heave could be a source of extraneous noise. 
The surface cover was modified in November 2015 (from black culvert with a metal lid to white culvert with a wooden lid), and differences in $\mathrm{AE}$ measurements before and after the modification were analyzed to investigate the effect of thermal expansion and contraction of the surface cover on the amount of $\mathrm{AE}$ data spikes.

\subsubsection{Effect of Cover Design on Extraneous Noise}

391 The original cover for the AE sensor consisted of a black plastic culvert base covered by a metal lid

392 (Figure 12a). Since it was found that changes in temperature resulted in large AE spikes in June and 393 September of 2015, it was theorized that solar radiation could be causing thermal expansion and 394 contraction of the metal lid leading to strains in the cover/foundation and generating AE. A new cover 395 was installed to test this hypothesis (Figure 12b). Since the black culvert would also lead to larger 396 amounts of solar radiation, the sides of the cover were painted white. The new cover was installed in 397 November of 2015. By comparing the cumulative AE and cumulative displacement over a 6 month 398 period when the original cover was in place (2014/2015) and the same 6 month period the following year $399(2015 / 2016)$ after the new cover design was installed, the effect of the cover design on the amount of noise present in the AE data can be analyzed. The six month period being considered includes the winter months since more noise was shown to be present in the data during the winter (Figure 12a). period with the original cover design is almost an order of magnitude larger than the AE measured with the new cover design. This larger amount of AE is independent of slope displacement since the displacement measured using the SAA for the two time spans varies by less than a factor of 2 (Figure 12d), and active waveguide-generated AE rates are proportional to slope displacement rates (Section 1.3). 
This shows that the cover design plays a significant role in the efficacy of the AE monitoring approach; a cover that produces spurious AE could lead to false alarms, reducing the reliability of the system.

\subsubsection{Use of Shallow AE Sensor to Filter Noise}

412 Although the cover design was found to cause significant extraneous noise, other sources of noise

413 remained. An additional source of this contamination could be surficial processes that are independent of

414 slope deformation (e.g. frost heave), which cannot easily be filtered from the AE measurements.

415 Therefore, a second waveguide (Shallow AE Sensor) was installed to measure this extraneous AE so that 416 it could be removed directly from AE measured by the Deep AE Sensor.

Figure 13a shows time series of measurements from both AE sensors and the SAA. Both AE sensors

419 follow the same trend and detect a large AE measurement in December of 2015. Figure 13b shows time

420 series of the filtered AE data (by removing AE measured by the shallow sensor from AE measured by the 421 deep sensor during each time interval) and the SAA shear surface displacement measurements for the 422 period November 2015 to May 2016. Both time series in Figure 13b exhibit comparable trends in 423 behavior. Cumulative filtered AE measurements are plotted against SAA shear surface displacement 424 measurements in Figure 13c to establish a correlation. It was found that a strong linear correlation exists 425 between the measured SAA displacement and the AE measurements with an $\mathrm{R}^{2}$ value of 0.93 . Based on 426 the relationship shown in Figure 13c, a cumulative (filtered) RDC value of 85500 corresponds to $1 \mathrm{~mm}$ of 427 displacement for the AE system installation at Peace River. 
Early warning systems for slope instability need to alert users of accelerating slope deformation behavior information on the rate of slope displacement so that accelerating movements indicative of incipient failure can be detected and communicated to responsible persons so that appropriate action can be taken.

434 An approach to convert AE rate measurements to the velocity of slope movement is therefore required.

435 To achieve this, a quantification framework to calibrate AE system installations was developed by Smith

436 (2015) using laboratory and field experiments, which included parameters for: AE attenuation (i.e. the

437 magnitude of lost energy as the AE propagates along the waveguide from the active zone in the

438 subsurface to ground level); backfill type and properties; waveguide geometry and properties; and sensor

439 settings and configuration.

441 Figure 14 shows the measured (filtered) AE rate versus SAA measured velocity relationship for the 442 installation at Peace River, using 90-day moving averages of measurements from the period November 4432015 to May 2016. The strong correlation demonstrates the ability of the AE technique to detect changes 444 in rates of movement.

446 The purpose of the AE system is to provide an early warning of slope failure by detecting and quantifying

447 increasing rates of movement. Accelerating slope behavior progresses over orders of magnitude; the 448 standard landslide velocity scale varies from extremely slow $(1 \mathrm{~mm} / \mathrm{yr})$ to extremely rapid $(1 \mathrm{~m} / \mathrm{s})(\mathrm{Cruden}$ 449 and Varnes, 1996). The velocity in the measured relationship in Figure 14 ranges from approximately $450 \quad 0.0001$ to $0.0007 \mathrm{~mm} / \mathrm{hr}$, which demonstrates the sensitivity of the AE approach to changes in 451 displacement rates. It is expected that if the slope began to accelerate, AE rates would increase 452 proportionally with displacement rates, as has been shown in previous studies (detailed in Section 1.3). 
The AE rate/velocity relationship in Figure 14, calculated for the installation at Peace River, is more than an order of magnitude larger than the predicted relationship using the framework detailed in Smith (2015)

456 (i.e. the AE rates generated by the system at Peace River in response to applied rates of slope movement

457 were significantly greater than predicted). This discrepancy is hypothesized to be due to a series of factors 458 that were not incorporated in Smith (2015)'s framework, which include: shear zone thickness; backfill 459 stress level, which increases with depth and governs the magnitude of inter-particle contact stresses and 460 hence AE energy; and the size of the active zone (i.e. backfill volume being deformed, which is 461 influenced by borehole diameter and active gravel backfill length). It is also possible that voids in the 462 bentonite/clay backfill reduced the magnitude of attenuation as AE propagated from the subsurface to 463 ground level. Smith (2015)'s framework was developed using cases of slopes with shallow shear surfaces

464 and hence low backfill stress levels. Furthermore, the active backfill volume in the Peace River 465 installation is an order of magnitude larger than those used in the physical model tests to develop the 466 framework (Smith, 2015; Smith et al., 2016a).

The higher than expected $\mathrm{AE}$ rate/velocity relationship indicates that although the level of $\mathrm{AE}$ attenuation 469 during propagation along the steel waveguide increases with depth to the shear surface, which initially 470 was thought could limit the possible shear surface depths that can be monitored, elevated stress levels 471 with depth and larger active zones significantly increase the magnitude of generated AE, compensating 472 for the experienced attenuation. This indicates that greater shear surface depths can be monitored than 473 previously anticipated. Further research is required to understand fully the link between backfill stress 474 level, active backfill volume, shear zone thickness and generated AE rates. 


\section{Conclusion}

477 Landslides in the Peace River region, Alberta, Canada, cause repeat damage to highways and utilities

478 infrastructure and, occasionally, movement accelerates, and potentially catastrophic slope failures occur.

479 The purpose of this study was to enhance understanding of the patterns of movement in these creeping

480 landslides and to trial an Acoustic Emission (AE) monitoring system, which was developed to detect and

481 communicate accelerating rates of slope movement indicative of incipient failure for use in early warning.

482 The principal findings are summarized in the following conclusions.

(a) A long-term dataset has been obtained for a case study landslide in Peace River. The landslide moves with an average displacement rate of $5 \mathrm{~mm} / \mathrm{yr}$ and is therefore classified as 'extremely slow'. High temporal resolution SAA measurements revealed that the slope experiences seasonal movement with higher displacement rates in January, April and August. The piezometric head measurements varied by more than 5 m over the 2010-2016 record, reaching a peak in 2013 of nearly $5 \mathrm{~m}$ above the piezometer tip, which is installed in the shear zone, and causing $12 \mathrm{~mm}$ of displacement that year (more than double the average displacement measured between 2010 and 2016). At values of piezometric head below a threshold value of $3 \mathrm{~m}$, no relationship between landslide velocity and piezometric head was observed. In contrast, at piezometric values higher than this threshold, a linear relationship between piezometric head and the average slope velocity was observed, with a $1 \mathrm{~m}$ increase in head resulting in a $0.015 \mathrm{~mm} /$ day increase the velocity of slope movement. It is not expected that this linear relationship would continue indefinitely with higher pore water pressures since the slope will accelerate as it approaches failure, illustrating the continued need for deformation rate-based landslide early warning sensors.

(b) Although the AE instrumentation monitors high frequencies (above $20 \mathrm{kHz}$ ) to filter lowprocesses (e.g. frost heave) and/or the cover responding to thermal effects. Modifying the surface 
cover to minimize thermal effects by changing a black culvert and metal lid for a white culvert with wooden lid was observed to reduce this noise by an order of magnitude. In addition, a shallow waveguide installed adjacent to the active waveguide was used to measure AE generated by the cover and/or surficial processes, which was then successfully removed from the AE measured by the active waveguide to obtain only AE highly correlated with subsurface ground movement.

(c) Comparisons between continuous SAA deformation measurements and filtered cumulative AE measurements provide evidence that the $\mathrm{AE}$ technique is able to measure 'extremely slow' rates of movement. The $\mathrm{AE}$ and deformation measurements exhibit the same trends in behavior and, when plotted against each other, display strong correlation.

(d) A calibration relationship was established using AE rate and slope velocity measurements, which can now be used to derive slope displacement rates from measured AE rates in the future for use in early warning. This measured $\mathrm{AE}$ rate/slope velocity relationship was more than an order of magnitude greater than a predicted relationship using the framework developed by Smith (2015). This is hypothesized to be due to greater shear zone thickness, backfill stress level and active backfill volume in the installation at Peace River than in the laboratory and field experiments used to develop Smith (2015)'s framework. This demonstrates that slopes with significantly greater shear surface depths can be monitored than previously expected, but further research is required to fully understand the link between backfill stress level, active backfill volume, shear zone thickness and generated $\mathrm{AE}$ rates.

Monitoring of this site will continue in order to better understand how the slope reacts to variations in pore water pressure and to further develop ways to detect the onset of slope failure.

\section{Acknowledgements}


The authors gratefully acknowledge funding from the Natural Sciences and Engineering Research Council and the support of Thurber Engineering Ltd in the form of invaluable assistance during the installation of instrumentation and long term field monitoring and through the funding of a Thurber Graduate Scholarship at Queen's University which was awarded to the first author. The authors are grateful to Alberta Transportation for their permission, encouragement and ongoing support to undertake the field study. The authors would also like to thank Kichton Contracting Ltd. for their help during the installation of the SAA and AE. The support provided by the Engineering and Physical Sciences this study.

\section{References}

Abdoun, T., Bennett, V., Desrosiers, T., Simm, J. \& Barendse, M. 2013. Asset Management and Safety Assessment of Levees and Earthen Dams Through Comprehensive Real-Time Field Monitoring. Geotechnical and Geological Engineering 31, No. 3, 833-843.

Bozzano, F., Cipriani, I., Mazzanti, P. and Prestininzi, A., 2014. A field experiment for calibrating landslide time-of-failure prediction functions. International Journal of Rock Mechanics and Mining Sciences, 67: 69-77.

Bressani, L.A., Pinheiro, R.J.B., Bica, A.V.D., Eisenberger, C.N. and SOARES, J., 2008. Movements of a large urban slope in the town of Santa Cruz do Sul (RGS), Brazil. CHEN, Z.; ZHANG, J.; LI, Z, 293-298.

Brunner, F.K., Woschitz, H. and Macheiner, K., 2007, November. Monitoring of deep-seated mass movements. In Proceedings of the Third International Conference on Structural Health Monitoring of Intelligent Infra-structure (SHMII-3), Vancouver, Canada: 13-16

Carey, J.M., Moore, R. and Petley, D.N., 2015. Patterns of movement in the Ventnor landslide complex, Isle of Wight, southern England. Landslides, 12(6): 1107-1118.

Chichibu, A., Jo, K., Nakamura, M., Goto, T. \& Kamata, M. 1989. Acoustic Emission Characteristics of Unstable Slopes. Journal of Acoustic Emission 8, No. 4, 107-112.

Cruden, D. M. \& Varnes, D. J. 1996. Landslides: Investigation and Mitigation. Chapter 3-Landslide types and processes. Transportation research board special report, (247). 
Dasenbrock, D., Levesque, C.L. and Danisch, L., 2012, June. Long-term rate behavior monitoring using automated MEMS-based sensing arrays in an urban landslide environment. In Proceedings of the 11th international and 2nd North American symposium on landslides, Banff, Alberta, Canada: 38

Davies, M R, Paulen, R C, and Hickin, A S. 2005. Inventory of Holocene Landslides, Peace River Area, Alberta (NTS 84C). Alberta Energy and Utilities Board.

Diyaljee, V. A., 2014, Stabilization of Roadway Landslide Using Anchored Drilled Shaft Piles Performance Evaluation over the Last 15 years. In proceedings of GeoCongress 2014.

Dixon, N., Hill, R., and Kavanagh, J. 2003. Acoustic emission monitoring of slope instability: development of an active wave guide system. Proceedings of the Institution of Civil Engineers, Geotechnical Engineering, 156: 83-95.

Dixon, N., Spriggs, M. P., Smith, A., Meldrum, P. \& Haslam, E. 2015a. Quantification of reactivated landslide behaviour using acoustic emission monitoring. Landslides 12, No. 3, 549-560. DOI: 10.1007/s10346-014-0491-z.

Dixon, N., Smith, A., Spriggs, M. P., Ridley, A., Meldrum, P. \& Haslam, E. (2015b) Stability monitoring of a rail slope using acoustic emission. Proceedings of the Institution of Civil Engineers Geotechnical Engineering 168 (5), 373-384.

Dixon, N., Codeglia, D., Smith, A., Fowmes, G.J. and Meldrum, P., 2015. An acoustic emission slope displacement rate sensor-case studies.

Fujiwara, T., Ishibashi, A. \& Monma, K. 1999. Application of acoustic emission method to Shirasu slope monitoring. In Slope stability engineering (Yagi, Yamagami \& Jiang (eds)). Rotterdam: Balkema: $147-150$.

Fukuzono, T., 1985, August. A new method for predicting the failure time of a slope. In Proceedings of the 4th International Conference and Field Workshop in Landslides, Tokyo (pp. 145-150).

Jaboyedoff, M., Ornstein, P. and Rouiller, J.D., 2004. Design of a geodetic database and associated tools for monitoring rock-slope movements: the example of the top of Randa rockfall scar. Natural Hazards and Earth System Science, 4(2): 187-196.

Koerner, R. M., McCabe, W. M. \& Lord, A. E. 1981. Acoustic emission behaviour and monitoring of soils. In Acoustic Emission in Geotechnical Practice, ASTM STP 750: 93-141.

Lerouil, S. Locat, J. Vaunat, J. Picarelli, L. Lee, H. Faure, R.. 1996. Geotechnical Characterization of slope movements. Landslides, Senneset (ed.). Balkema, Rotterdam: 53-74.

Macciotta, R, Hendry, M, Derek, C, Elwood, D, Lan, H, Huntley, D, Bobrowsky, P, Sladen, W, Bince, C, Choi, E, Edwards, T. 2014. Monitoring of the Ripley Landslide in the Thompson River Valley B. C. 6th Canadian Geohazards Conference, Kingston, Canada, Paper 122. 
Malet, J.P., Maquaire, O. and Calais, E., 2002. The use of Global Positioning System techniques for the continuous monitoring of landslides: application to the Super-Sauze earthflow (Alpes-de-HauteProvence, France).Geomorphology, 43(1): 33-54.

Massey, C.I., Petley, D.N. and McSaveney, M.J., 2013. Patterns of movement in reactivated landslides. Engineering Geology, 159: 1-19.

Michlmayr, G. \& Or, D. 2014. Mechanisms for acoustic emissions generation during granular shearing. Granular Matter 16, No. 5, 627-640.

Michlmayr, G., Cohen, D. \& Or, D. 2013. Shear-induced force fluctuations and acoustic emissions in granular material. Journal of Geophysical Research: Solid Earth 118, No. 12, 6086-6098.

Morgan, A J, Paulen, R C, Slattery, S R, and Froese, C R. 2012. Geological Setting for Large Landslides at the Town of Peace River, Alberta (NTS 84C). Energy Resources Conservation Board, ERCB/AGS OFR 2012-04.

Nakajima, I., Negishi, M., Ujihira, M. \& Tanabe, T. 1991. Application of the acoustic emission monitoring rod to landslide measurement. Proc. 5th Conf. on Acoustic Emission/Microseismic Activity in Geologic Structures and Materials, Pennsylvania: 1-15.

Rouse, C., Styles, P. \& Wilson, S. A. 1991. Microseismic emissions from flowslide-type movements in South Wales. Engng Geol. 31, No. 1, 91-110.

Saito, M., 1965. Forecasting the time of occurrence of a slope failure. Proceedings of the 6th International Conference on Soil Mechanics and Foundation Engineering, (2): 537 - 539.

Simeoni, L. and Mongiovì, L., 2007. Inclinometer monitoring of the Castelrotto landslide in Italy. Journal of geotechnical and geoenvironmental engineering,133(6): 653-666.

Smith, A. 2015. Quantification of slope deformation behaviour using acoustic emission monitoring. PhD thesis, Loughborough University.

Smith, A. \& Dixon, N. (2015). Quantification of landslide velocity from active waveguide-generated acoustic emission. Canadian Geotechnical Journal 52, No. 4, 413-425. DOI: 10.1139/cgj-20140226.

Smith, A., Dixon, N., Meldrum, P., Haslam, E. \& Chambers, J. 2014a. Acoustic emission monitoring of a soil slope: Comparisons with continuous deformation measurements. Géotechnique Letters 4, No. $4,255-261$.

Smith, A., Dixon, N., Meldrum, P. \& Haslam, E. 2014b. Inclinometer casings retrofitted with acoustic real-time monitoring systems. Ground Engineering, October Issue.

Smith, A., Dixon, N., Berg, N., Take, A. and Proudfoot, D., 2014c. Listening for landslides: method, measurements and the Peace River case study. Geohazards 6, Kingston, Ontario. 
621

622

623

624

625

626

627

628

629

630

631

632

633

634

635

636

637

638
Smith, A., Dixon, N. \& Fowmes, G. 2016a. Early detection of first-time slope failures using acoustic emission measurements: large-scale physical modelling. Géotechnique, Sept., DOI: http://dx.doi.org/10.1680/jgeot.15.P.200

Smith, A., Dixon, N., \& Fowmes, G. 2016b. Monitoring buried pipe deformation using acoustic emission: quantification of attenuation. International Journal of Geotechnical Engineering, 1-13. doi: $10.1080 / 19386362.2016 .1227581$

Spriggs, M. 2005. Quantification of acoustic emission from soils for predicting landslide failure. $\mathrm{PhD}$ thesis, Civil and Building Engineering, Loughborough University, UK.

Stark, T.D. and Choi, H., 2008. Slope inclinometers for landslides. Landslides, 5(3): 339-350.

Thurber Engineering. 1987. Alberta Transportation Report on Realignment of Highway at CN Crossing. Report prepared for Alberta Transportation.

Thurber Engineering. 2009. Alberta Transportation Geohazard Assessment Program Part A: File Review. Report prepared for Alberta Transportation. File Number: 15-16-213A.

Uhlemann, S., Smith, A., Chambers, J.E., Dixon, N., Dijkstra, T., Haslam, E., Meldrum, P.I., Merritt, A.J., Gunn, D.A., and Mackay, J., 2016. Assessment of ground-based monitoring techniques applied to landslide investigations. Geomorphology, 253, 438-451. 
a)

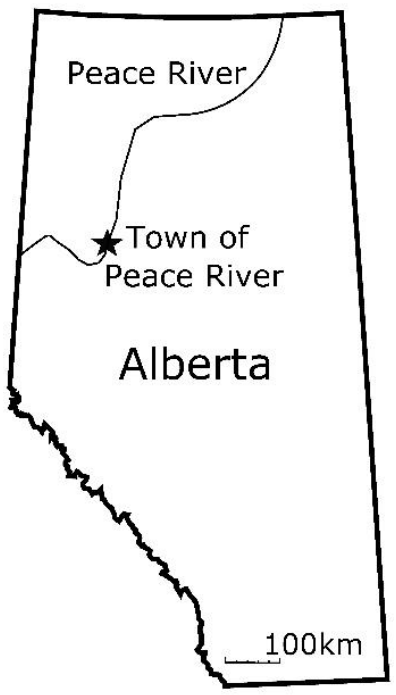

c)

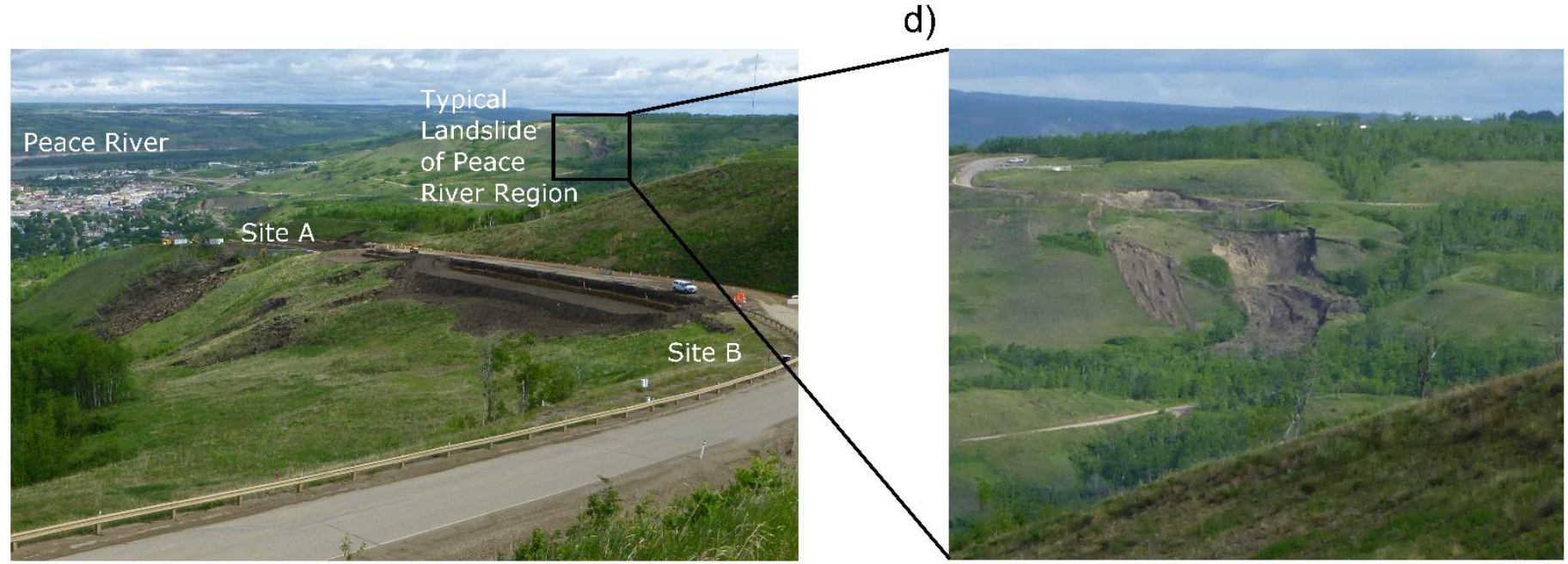

b)

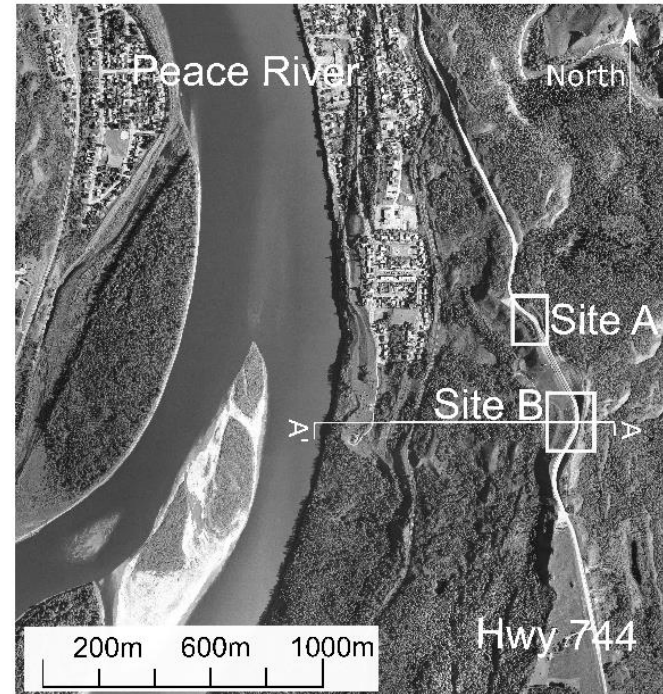

d)

Figure 1: a) Location of Peace River b) Location of two landslide sites along highway 744 near the town of Peace River, Alberta c) Image of site $A$ and $B$ as well as an example of a typical landslide in the area d) Close up view of landslide shown in the box on Figure 1c 
a)

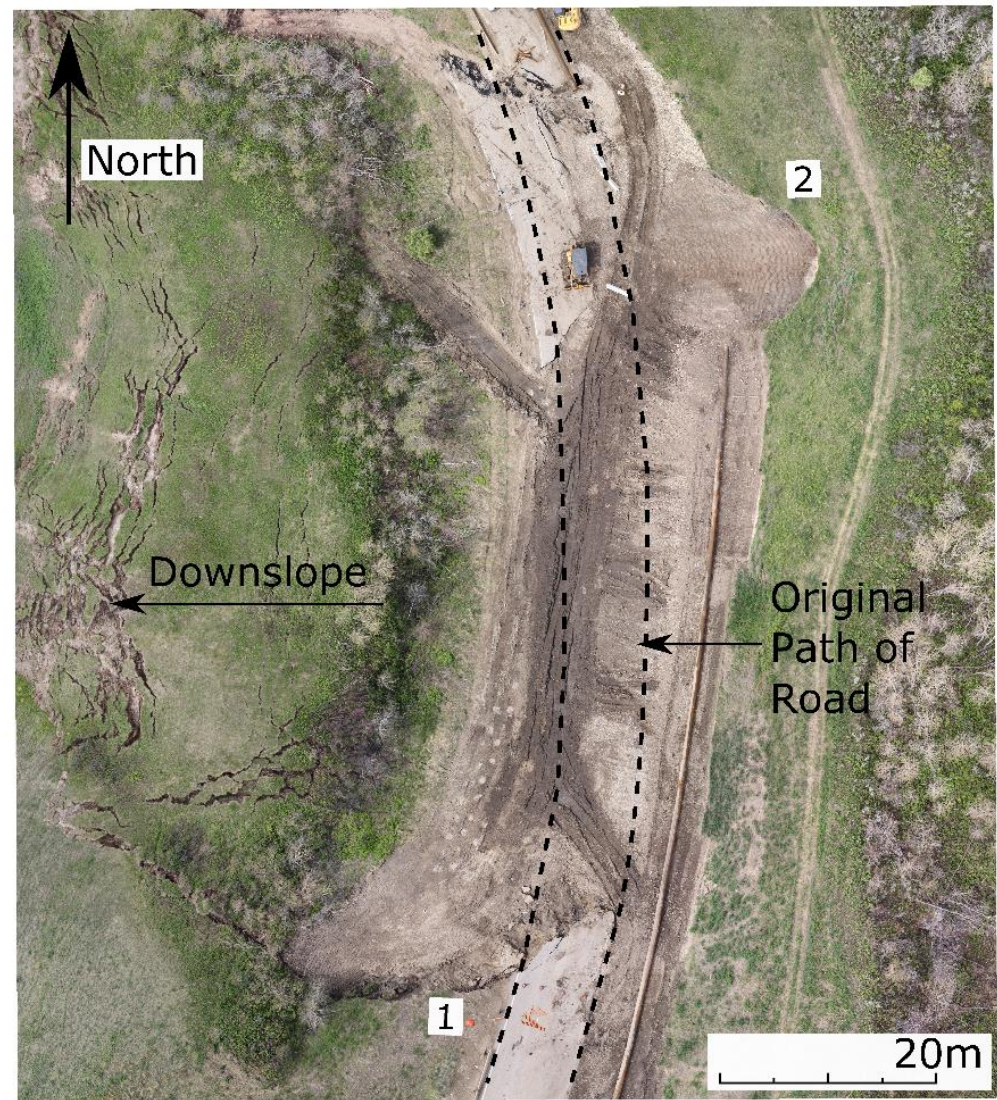

b)

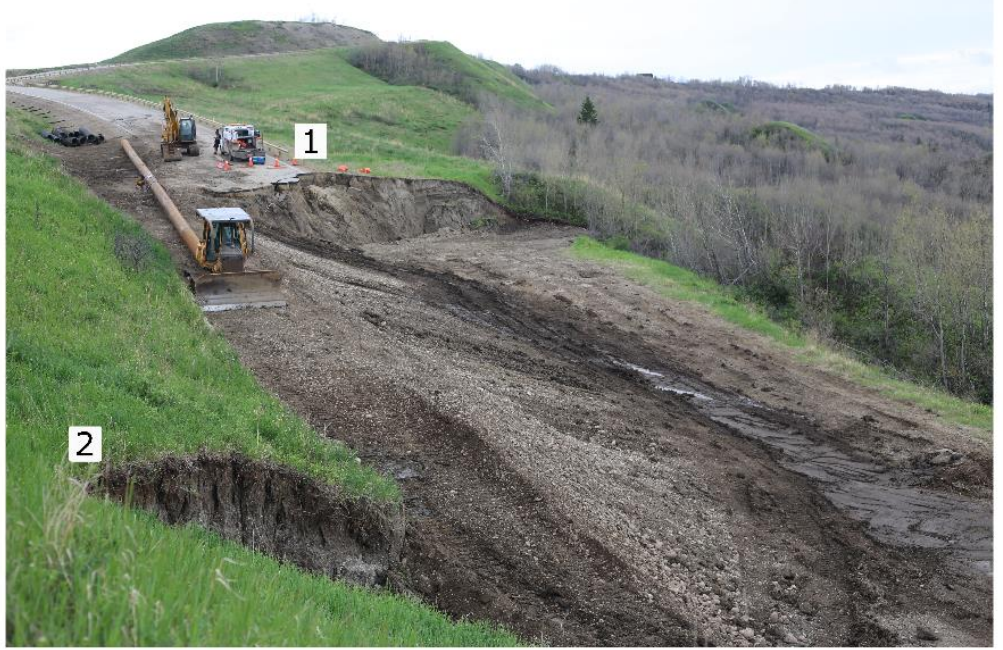

Figure 2: a) aerial photogrammetry model of slope with failures 1 and 2 b) Ground image, taken looking south, showing failures 1 and 2 along road 
a) Landslide accelerating to failure
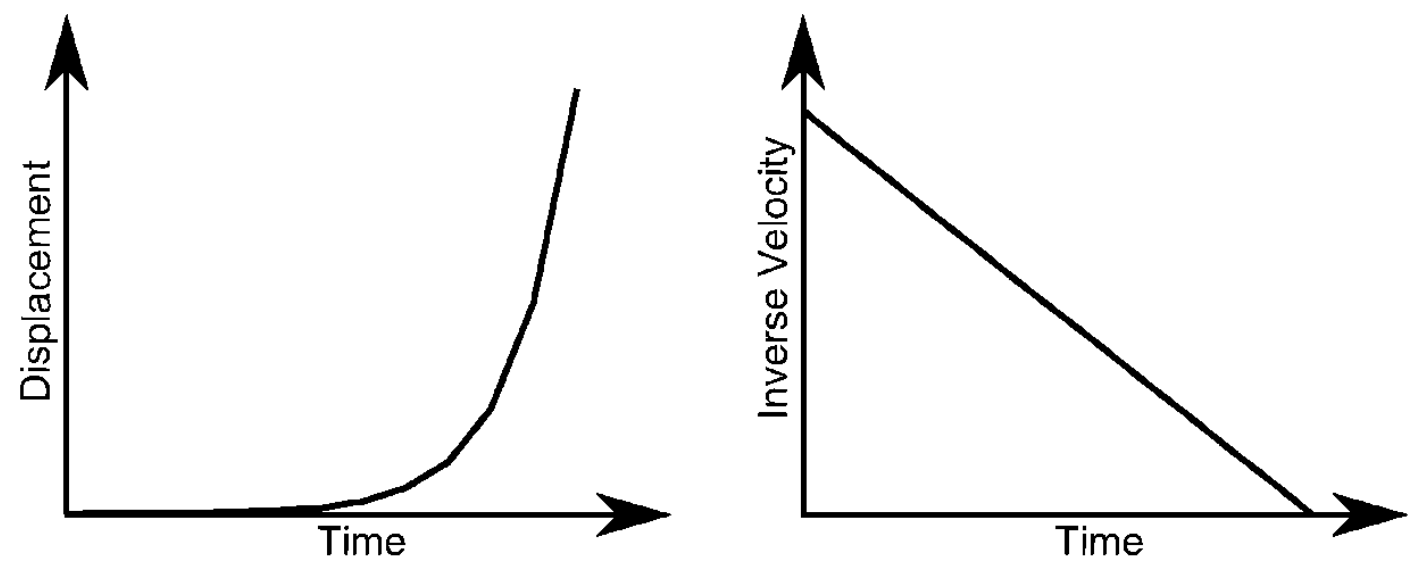

b) Seasonally active landslide
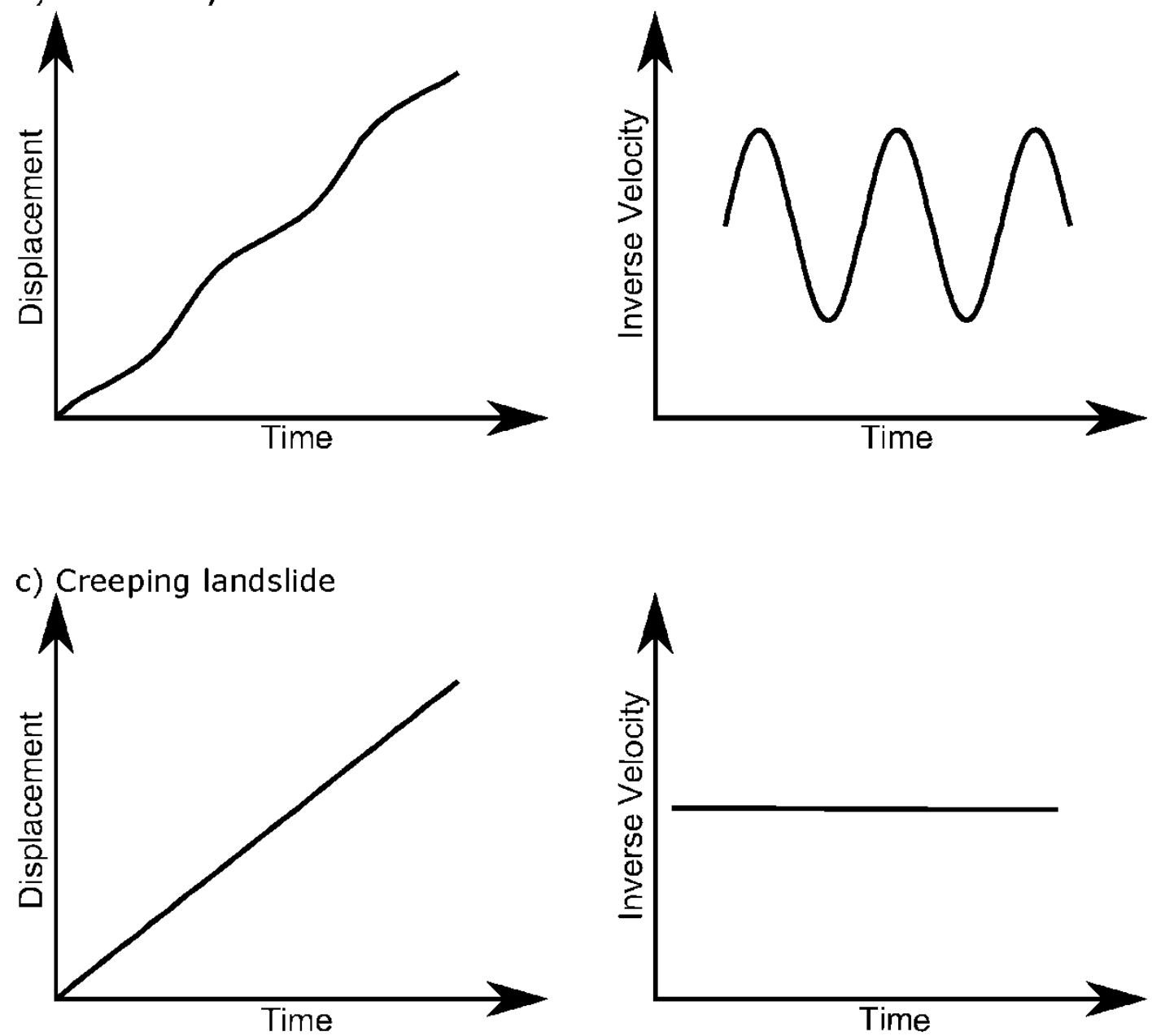

Figure 3: Idealized relationship of displacement and inverse velocity of a) landslide accelerating to failure b) seasonally activated landslides and c) creep displacement 
a) Slope Inclinometer

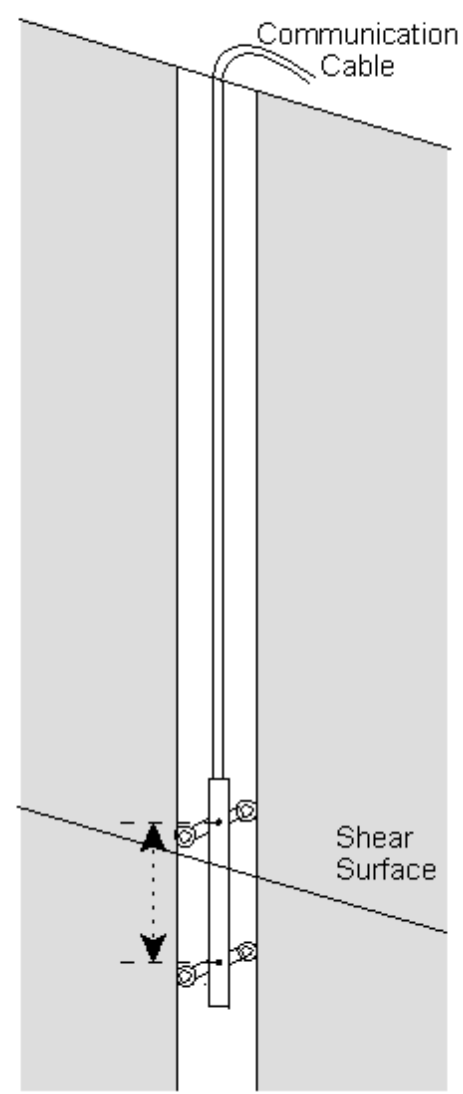

b) SAA

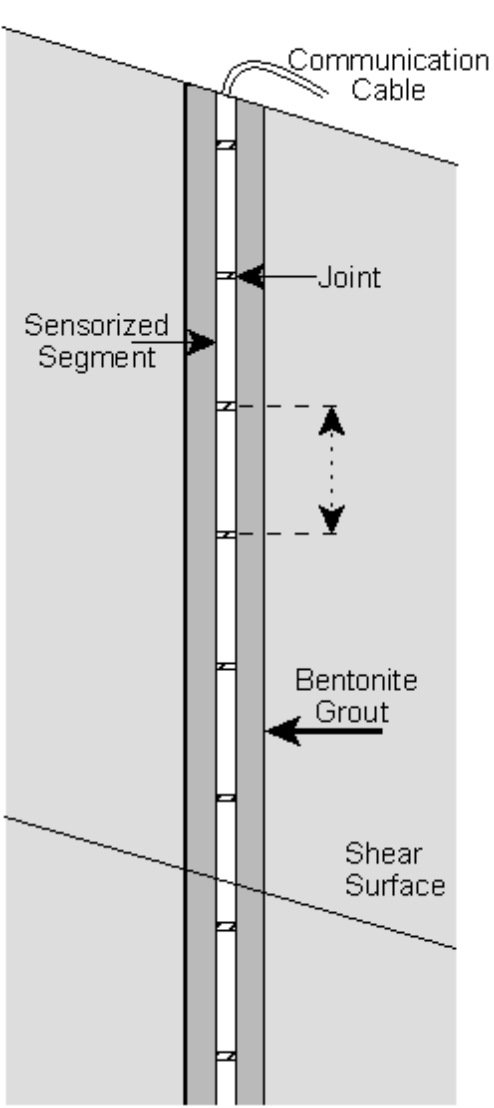

c) AE Sensor

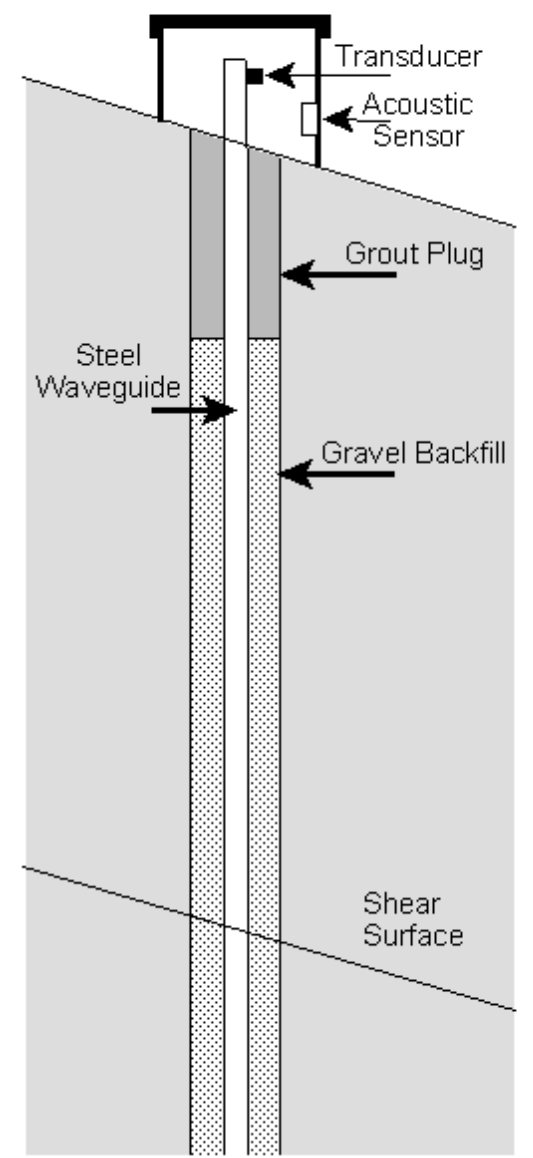

Figure 4: Methods used to monitor landslide displacement: (a) Inclinometer; (b) ShapeAccelArray; and (c) Acoustic Emission active waveguide 

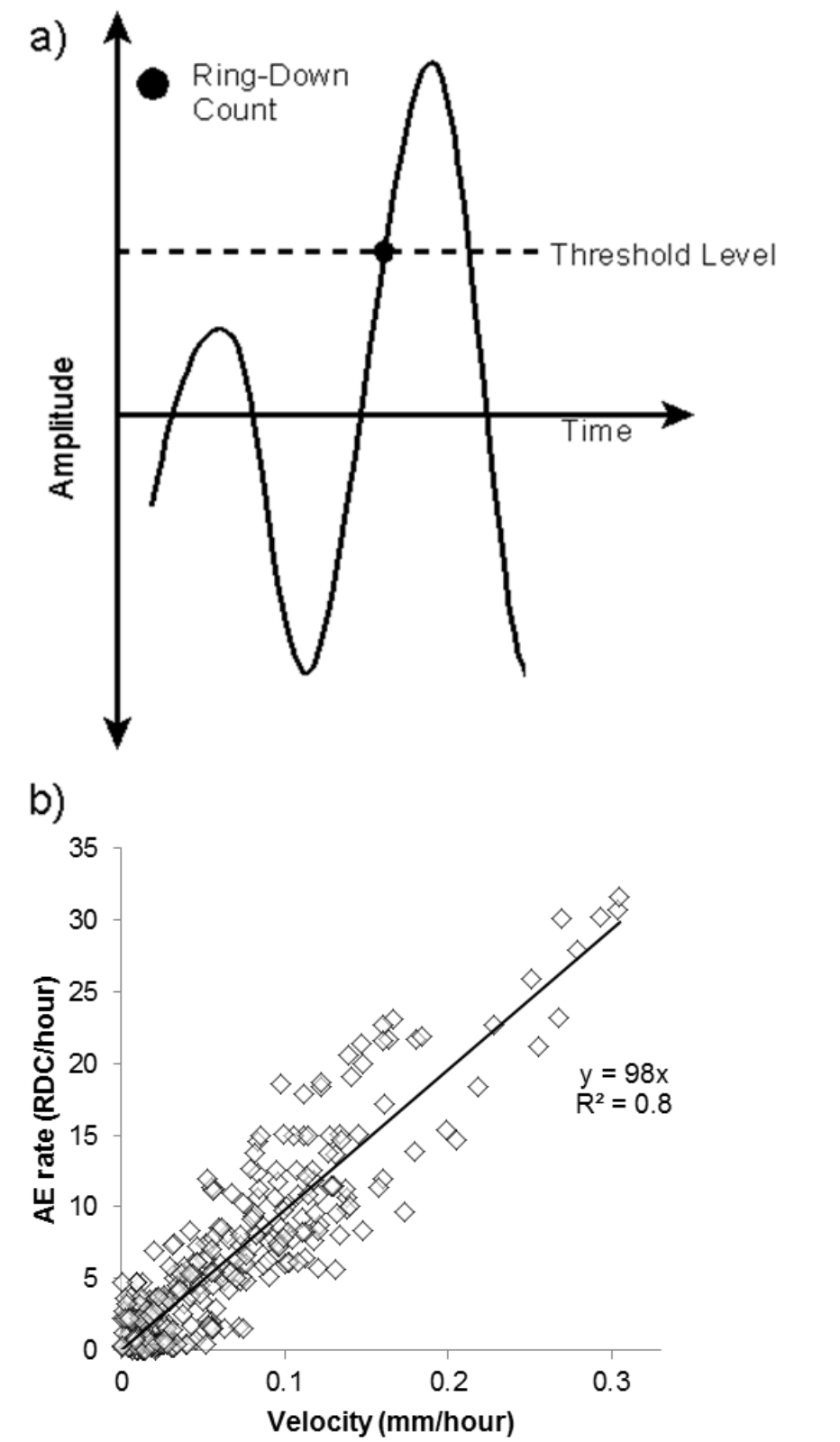

Figure 5: a) Illustration of AE amplitude versus time and RDC b) Relationship between measured $\mathrm{AE}$ rates and the velocity of slope movement from a shallow reactivated landslide (after Smith $e t$ al., 2014a; Smith et al., 2016a) 
a)

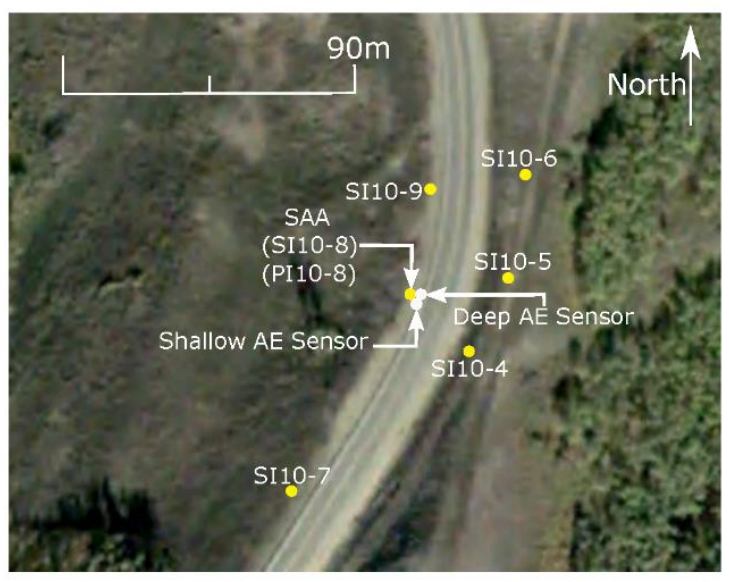

b)

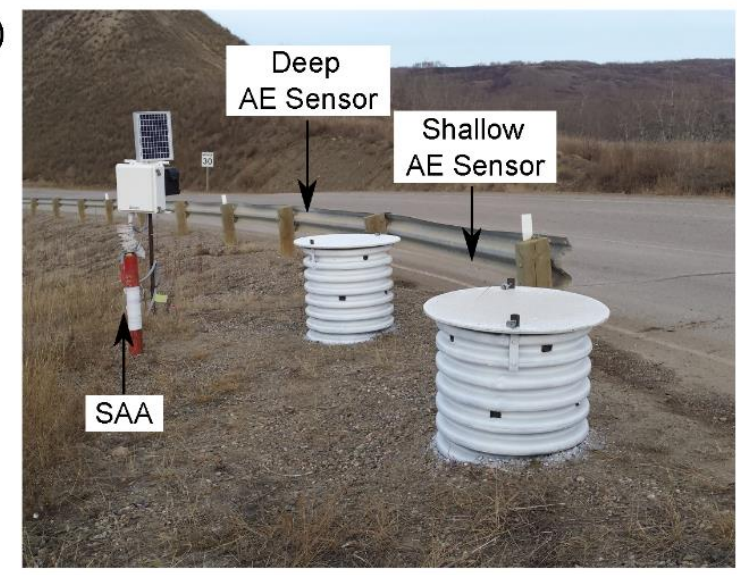

d)

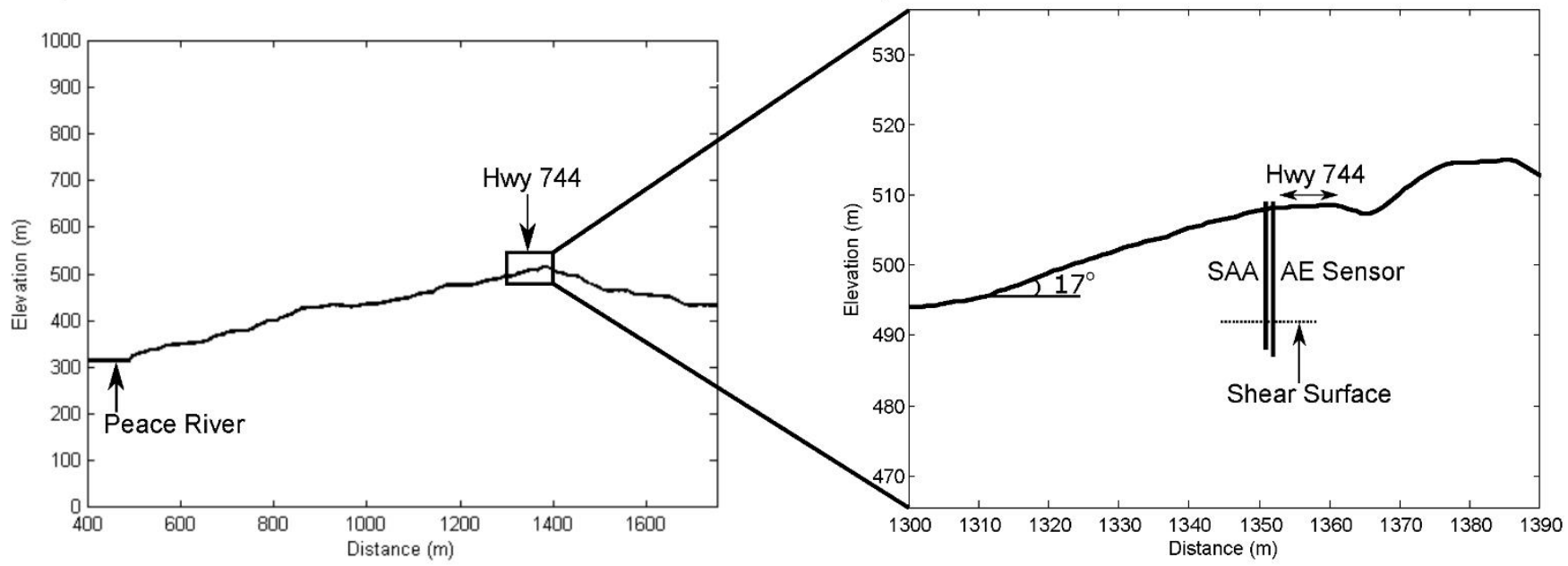

Figure 6: a) Location of sensors at Site B b) Proximity of AE and SAA sensors to highway 744 c) Cross section A-A' of Site B shown on Figure $1 \mathrm{~d}$ ) Close up of cross section shown in box in Figure 6c 


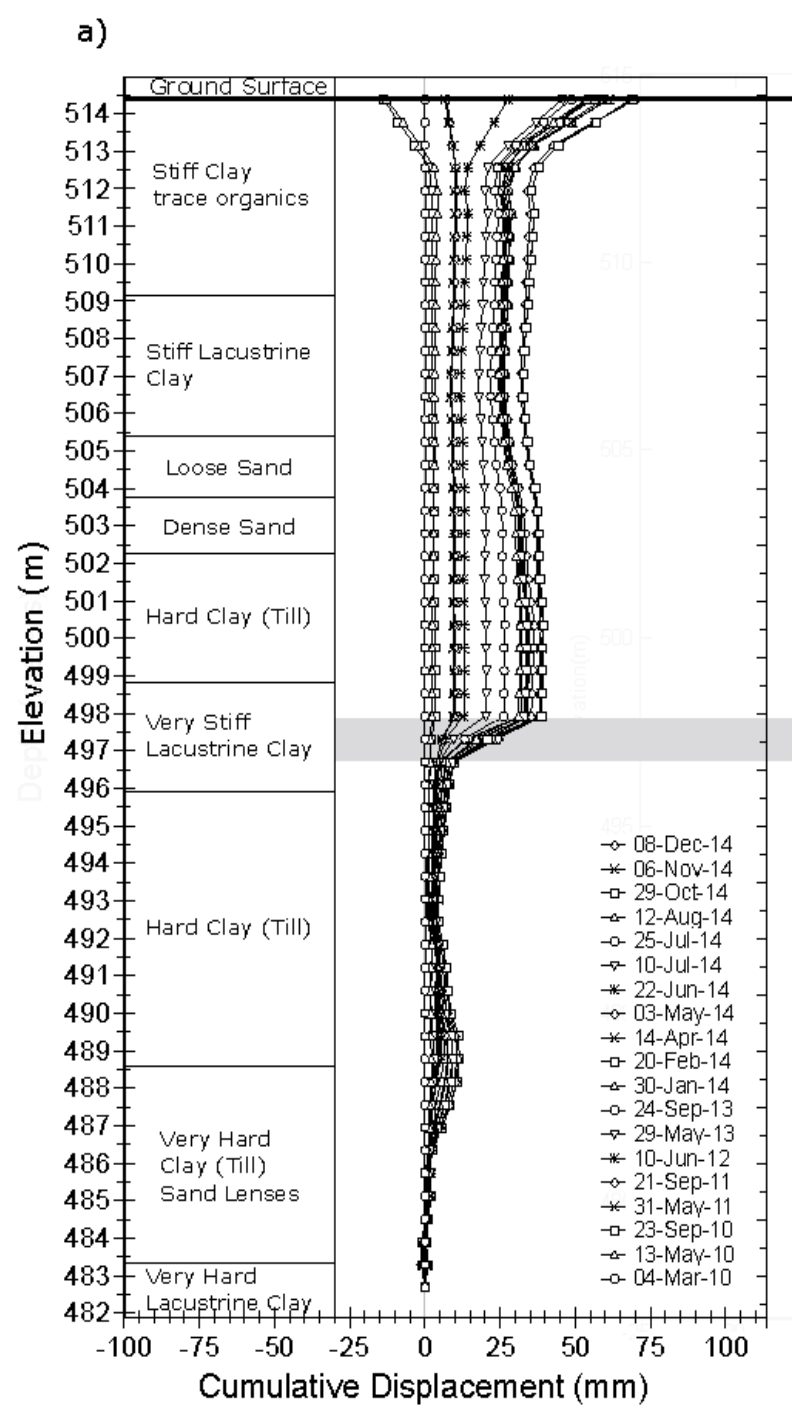

b)

c)

Deep $A E$

Shallow AE sensor

d)
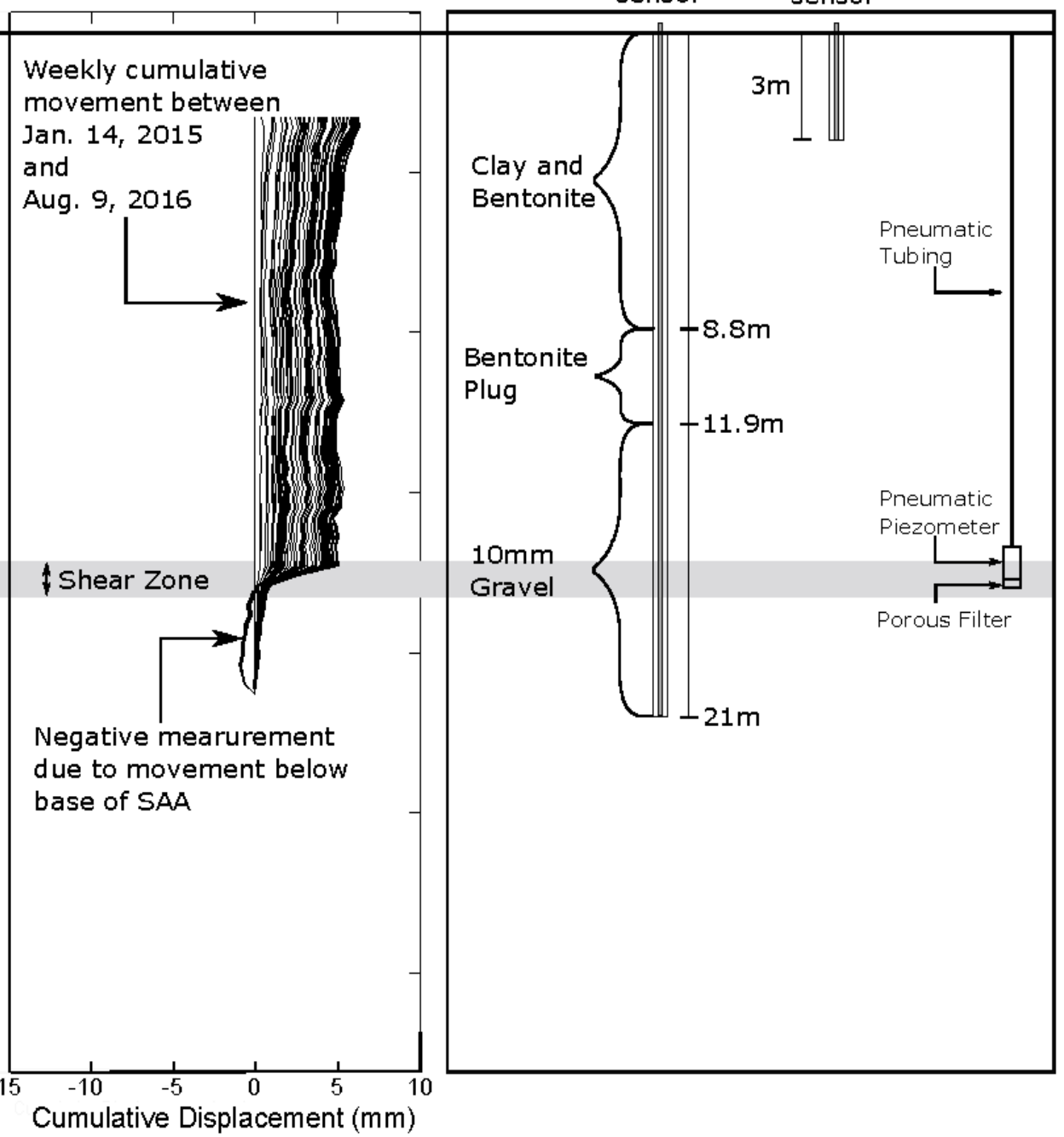

Cumulative Displacement $(\mathrm{mm})$

Figure 7: a) Inclinometer data with soil layers determined from borehole log data, b) Cumulative SAA data showing one failure surface at a depth of $16 \mathrm{~m}$, c) Sketch of installed Deep and Shallow AE Sensors at Site B in Peace River, Alberta, and d) Piezometer installation 


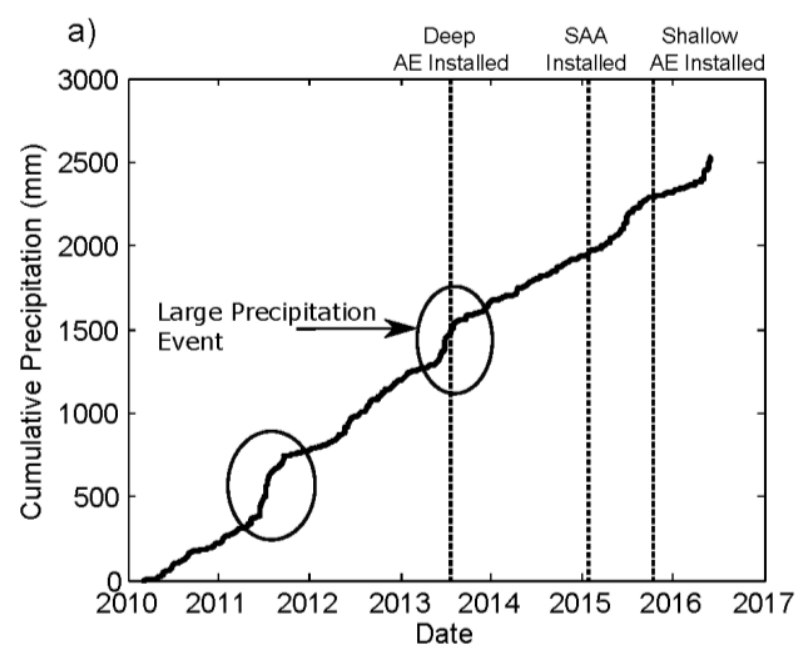

b)

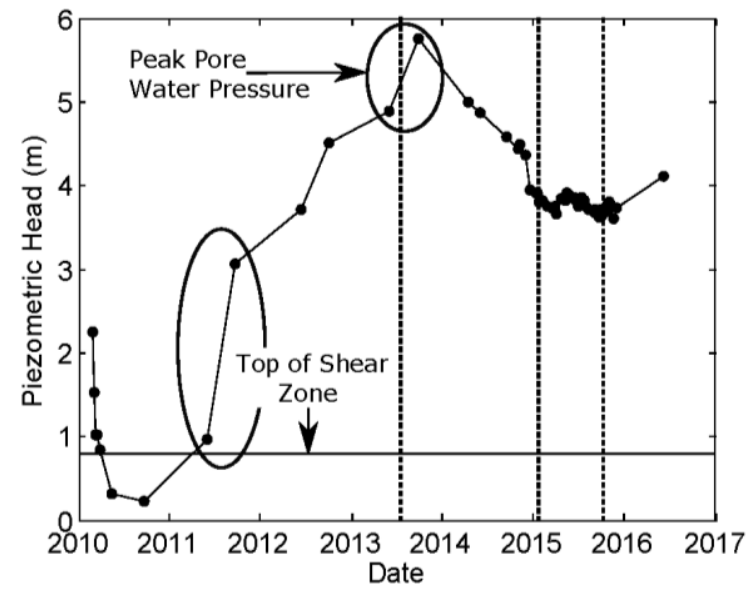

c)

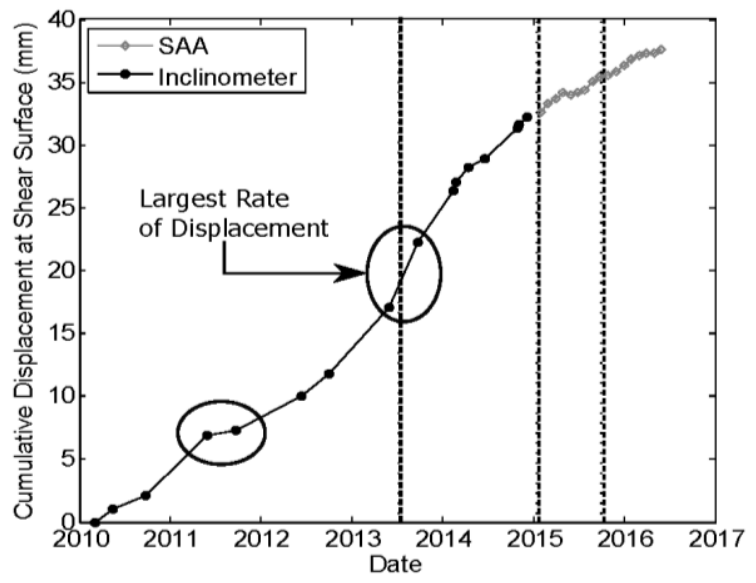

Figure 8: a) cumulative total precipitation, with timing of sensor installations highlighted b) piezometric head (above piezometer tip, which is installed in the shear zone) c) cumulative displacement measured at the shear surface from the inclinometer and SAA 


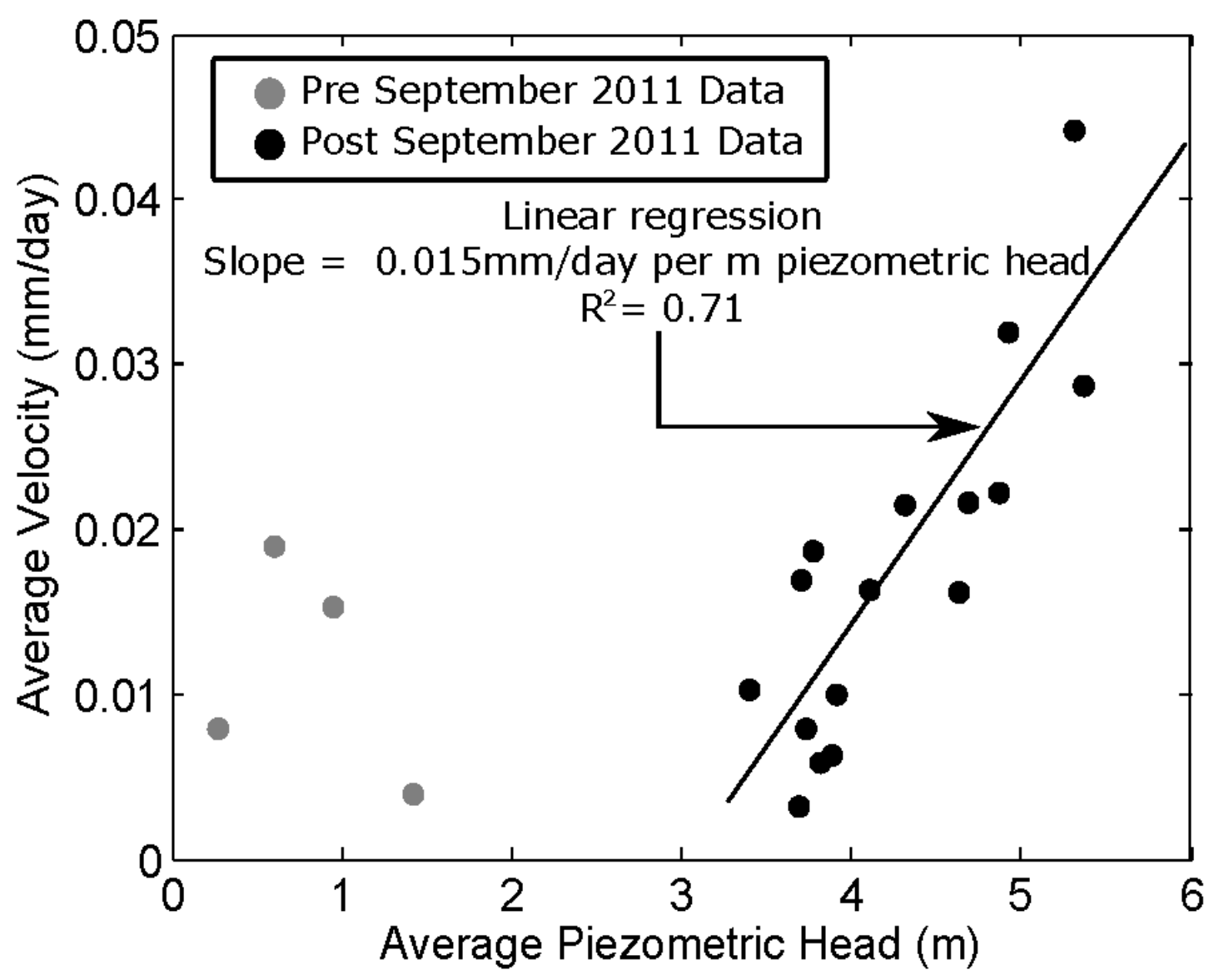

Figure 9: Relationship between average slope velocity and average piezometric head 
a)

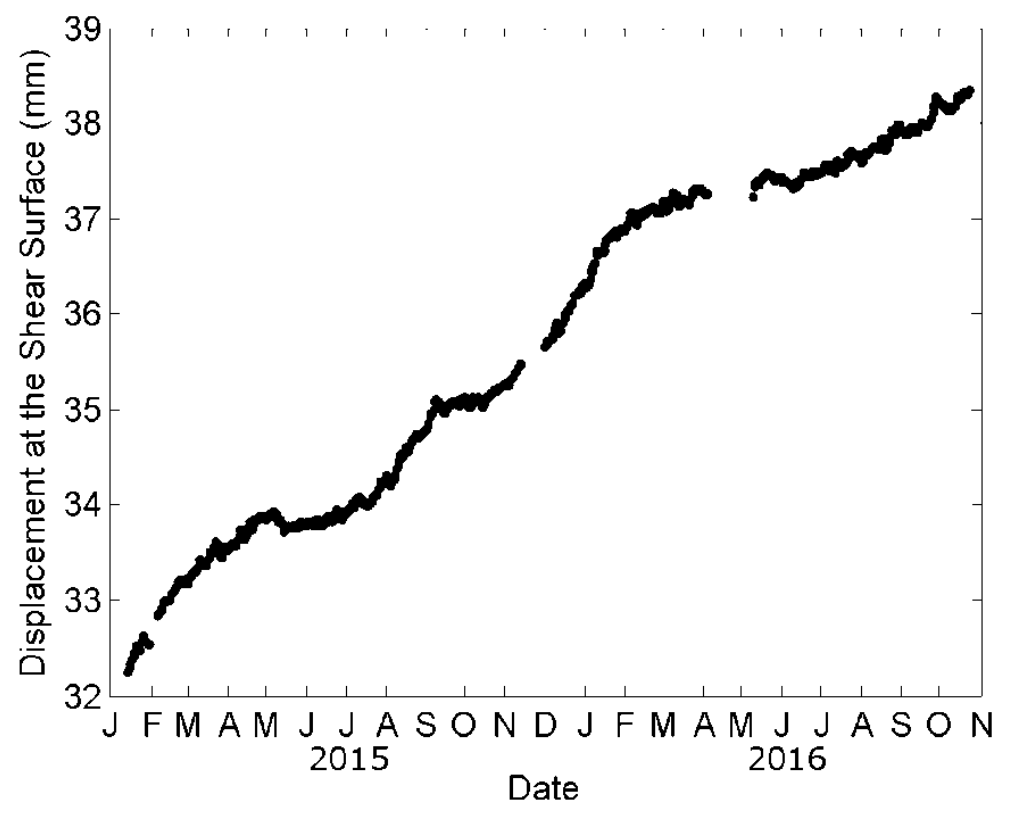

b)

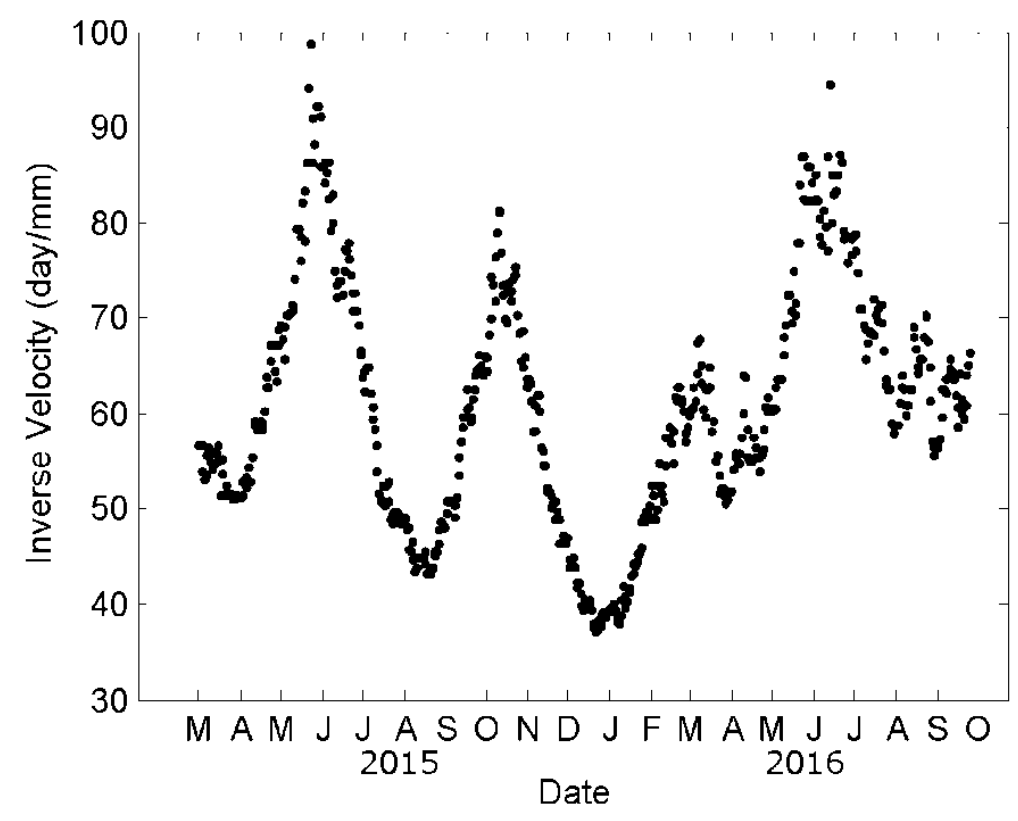

Figure 10: a) cumulative SAA-measured displacement at the shear surface b) Inverse SAA-measured velocity of the slope using a 60-day moving average 
a)

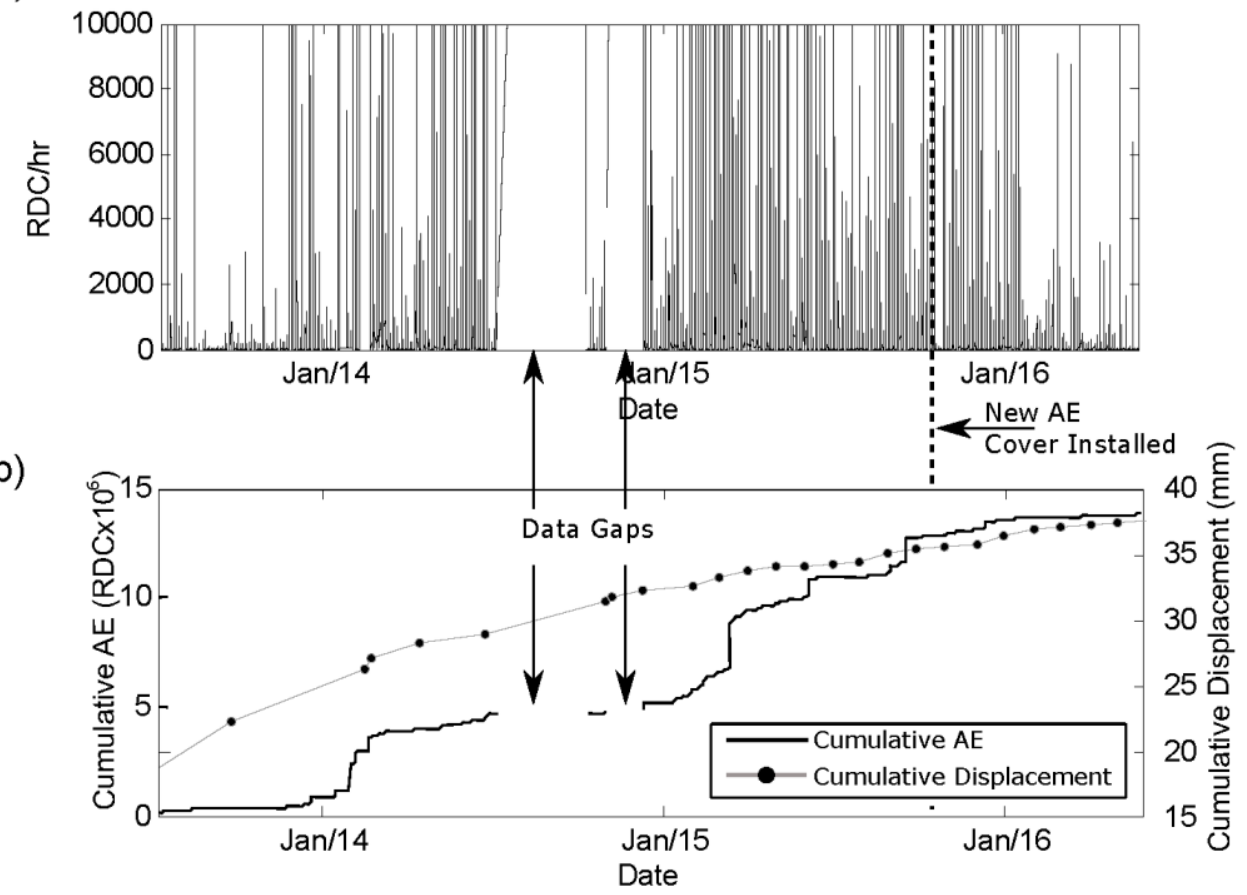

c)

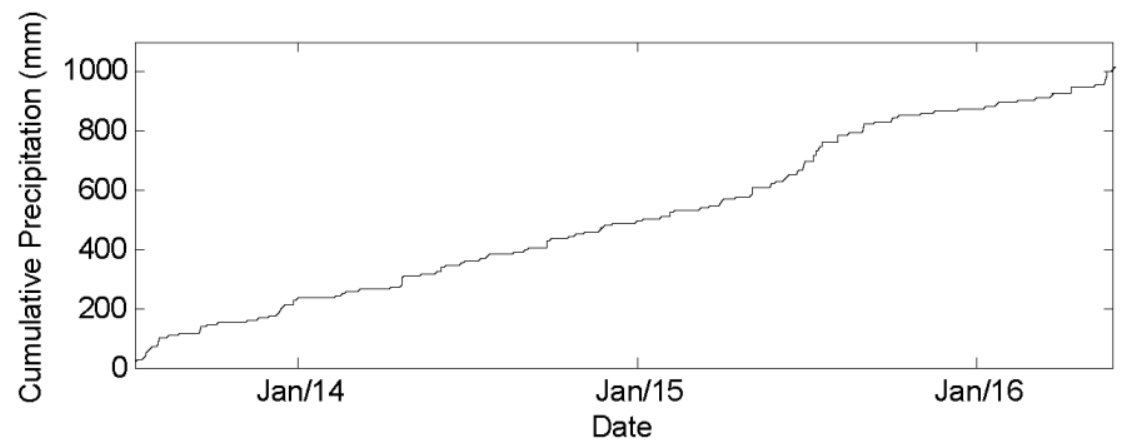

d)

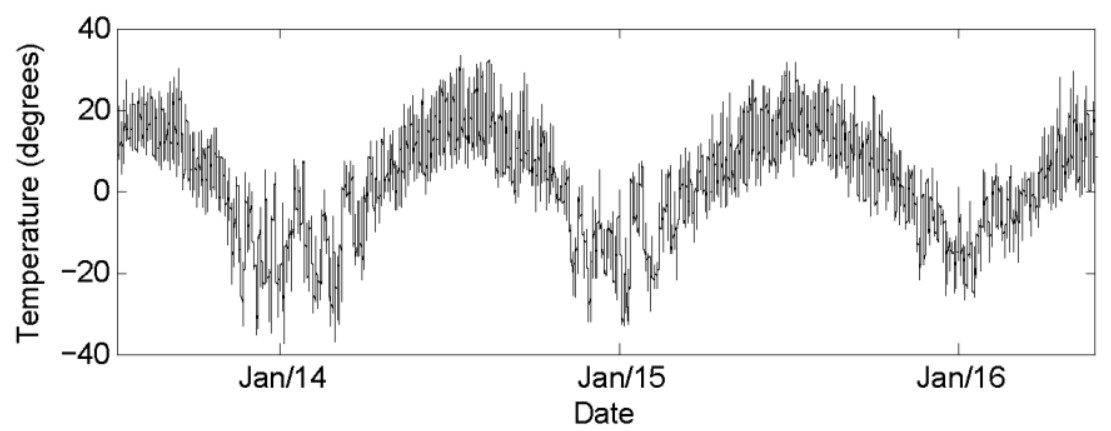

Figure 11: a) raw deep AE sensor data showing large spikes in measured RDC b) cumulative AE data $\left({\mathrm{x} 10^{5}}^{5}\right)$ from deep $\mathrm{AE}$ sensor and cumulative displacement c) cumulative daily total precipitation collected by Environment Canada d) hourly temperature data collected by Environment Canada 
Original Cover Design

a)

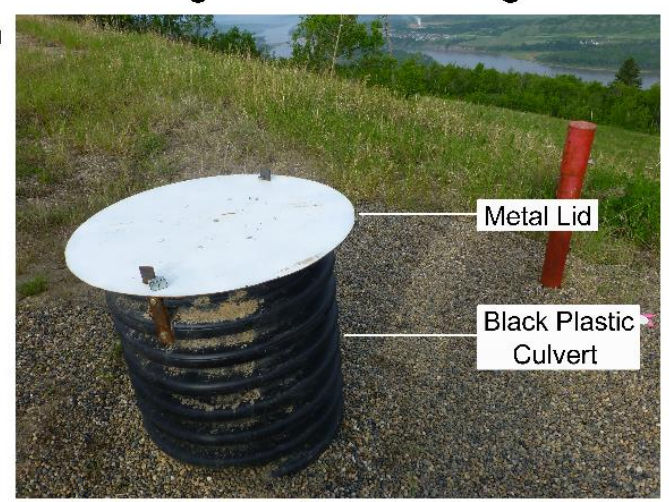

Modified Cover Design

b)

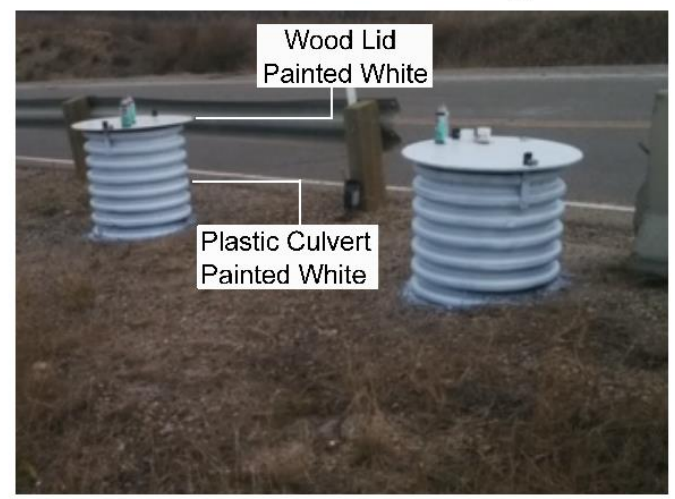

c)

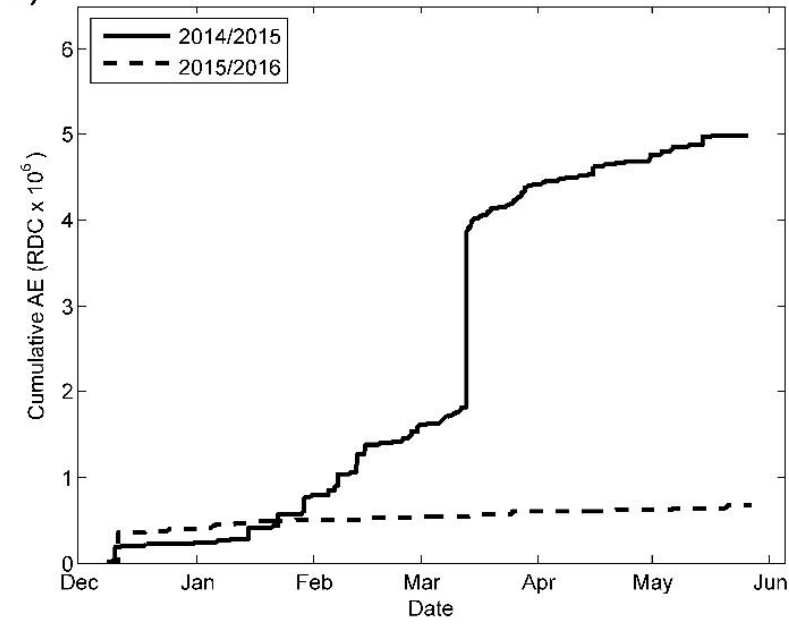

d)

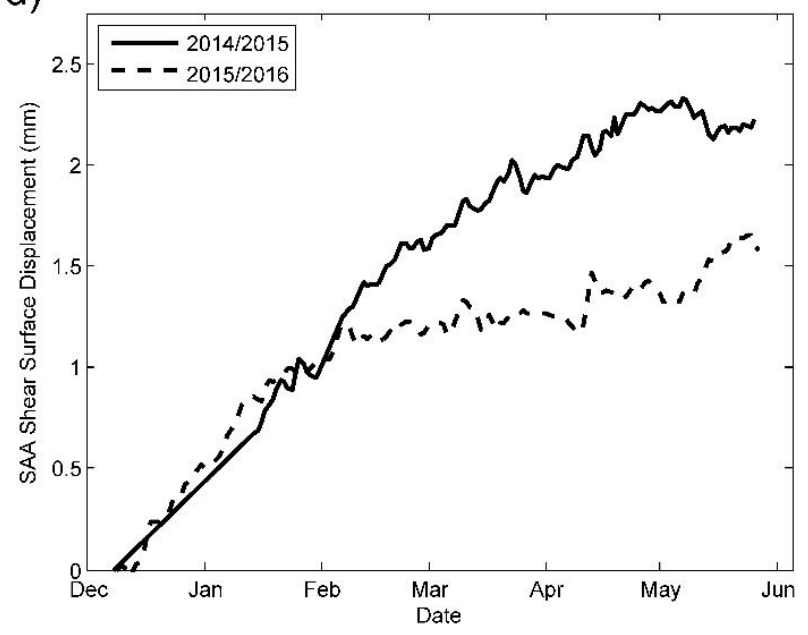

Figure 12: a) image of original cover design b) image of modified cover design after second $\mathrm{AE}$ sensor was installed c) cumulative AE ( $\left(\mathrm{CDC}_{\mathrm{x} 10^{6}}\right.$ ) measured over 6 month period in 2014/2015 and 2015/2016 d) cumulative displacement measured by SAA over a 6 month period in 2014/2015 and 2015/2016 
a)

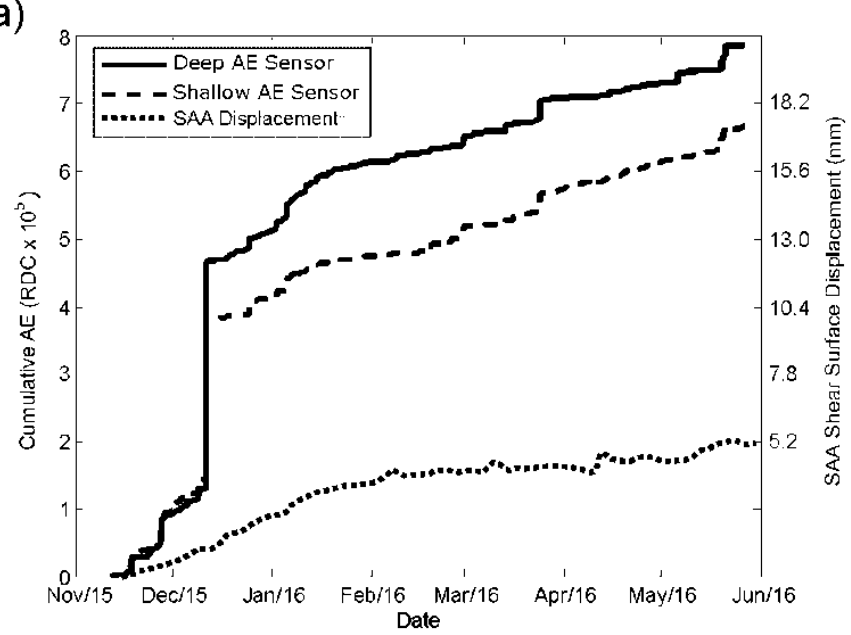

b)

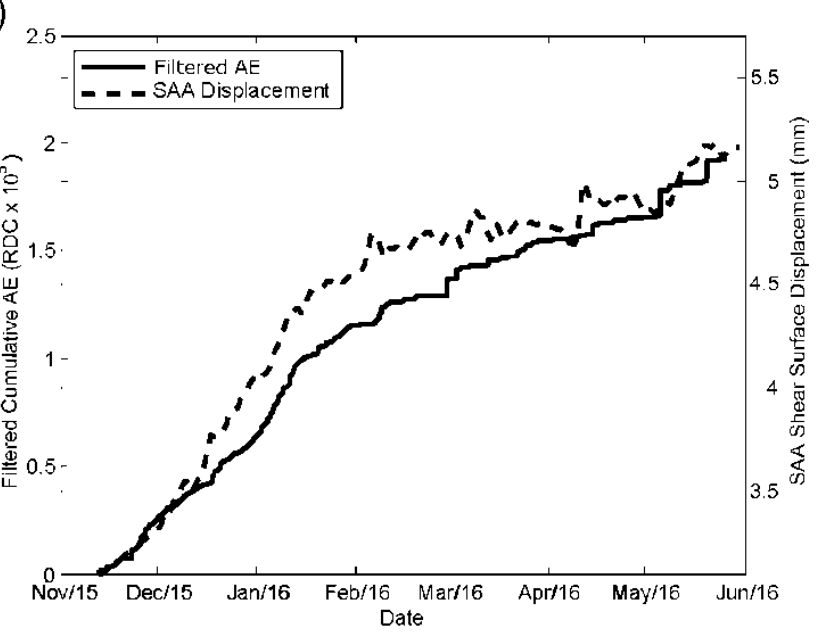

c)

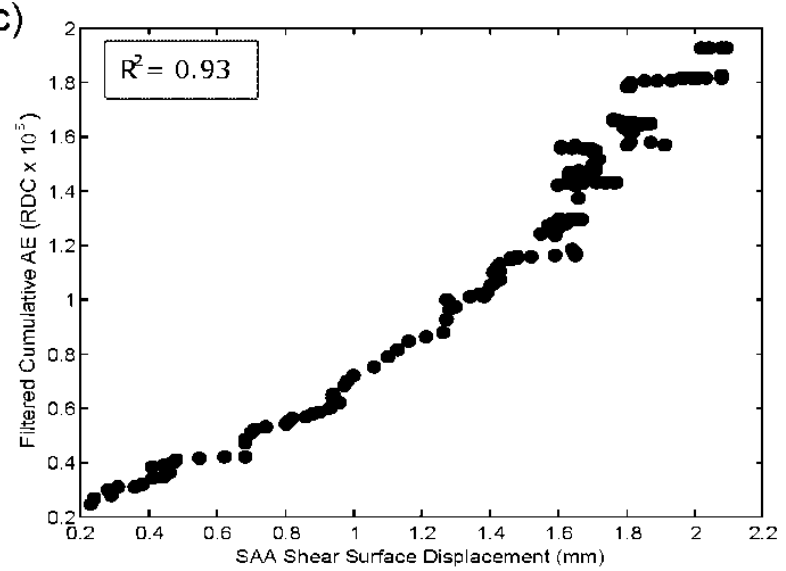

Figure 13 a) Comparison of cumulative $\mathrm{AE}\left(\mathrm{x10}^{5}\right)$ measured from deep and shallow sensors b) Comparison of filtered cumulative $\mathrm{AE}\left(\mathrm{x10}^{5}\right)$ data and displacement measured by SAA c) Relationship between filtered cumulative $\mathrm{AE}\left(\mathrm{x10}^{5}\right)$ data and displacement data from SAA 


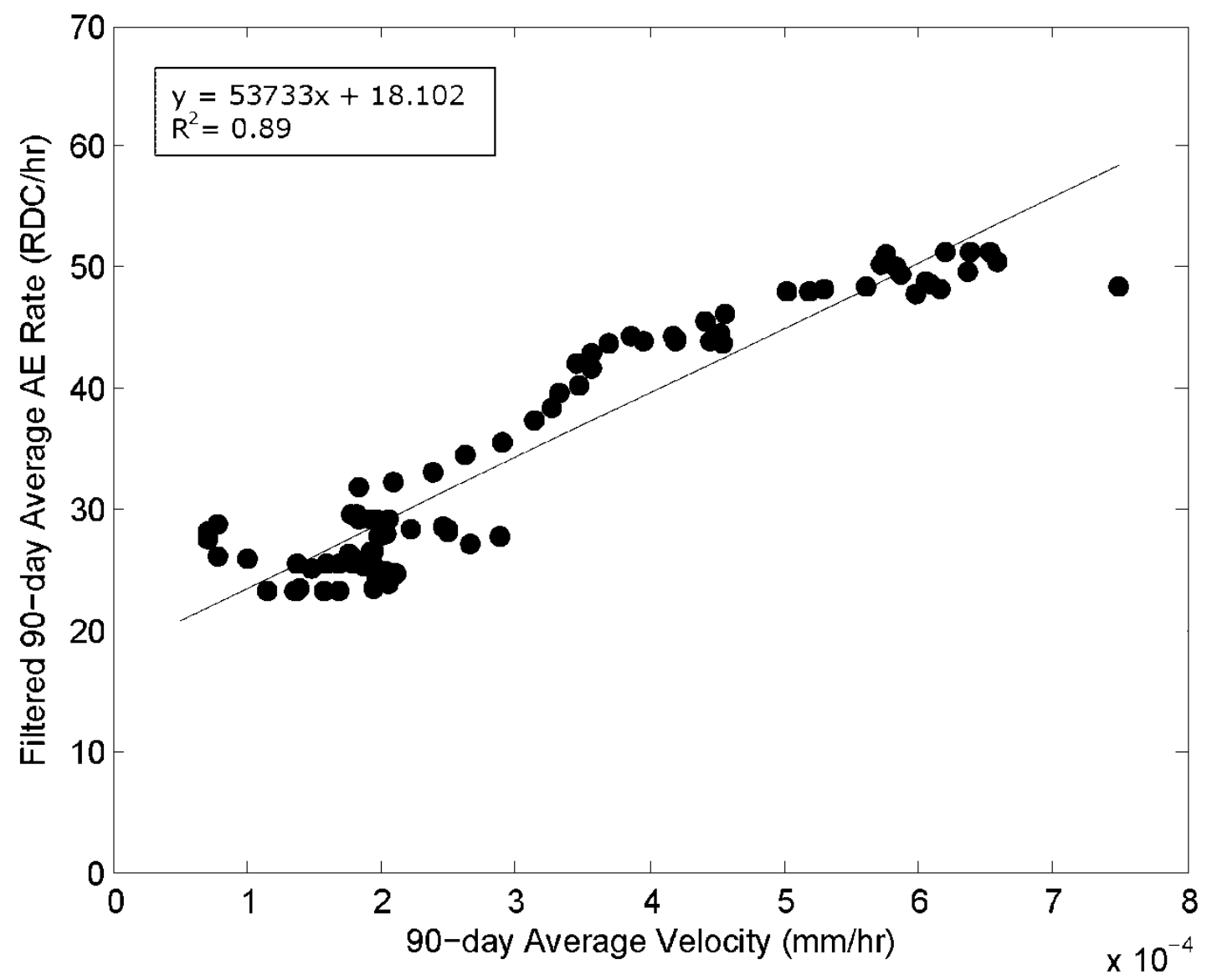

Figure 14: Measured AE rate -velocity calibration relationship for the installation at Peace River using 90-day moving averages 